\title{
Moisture expansion as a deterioration factor for sandstone used in buildings
}

\author{
Joerg Ruedrich • Tobias Bartelsen • \\ Reiner Dohrmann $\cdot$ Siegfried Siegesmund
}

Received: 24 June 2010/ Accepted: 26 September 2010/Published online: 17 October 2010

(C) The Author(s) 2010. This article is published with open access at Springerlink.com

\begin{abstract}
The expansion processes that develop in building stones upon changes of moisture content may be an important contributing factor for their deteriorations. Until recently, few data could be found in the literature concerning this parameter and weathering processes. Moreover, the processes that may be responsible for the moisture related expansion of natural building stones are not yet completely understood. To further elucidate this process, extensive mineralogical, petrophysical and fabric investigations were performed on eight German sandstones in order to obtain more information regarding the weathering process and its dependence on the rock fabric. The analysed sandstones show a wide range of pore size distributions and porosities. A positive correlation with the fabric and the pore space can be found for all studied petrophysical parameters. The intensity of the expansion and related swelling pressure cannot be attributed only to the swelling of clay minerals. The investigations suggest that the micropores and the resulting disjoining pressure during wet/dry cycles also play an important role. The results obtained suggest that the mechanism is related to the presence of liquid water within the porous material.
\end{abstract}

Keywords Sandstone weathering - Moisture expansion . Hygric and hydric wetting . Swelling clay minerals

\footnotetext{
J. Ruedrich $(\bowtie) \cdot$ T. Bartelsen · S. Siegesmund Geoscience Centre of the University Göttingen, Goldschmidtstr. 3, 37077 Göttingen, Germany e-mail: joerg.ruedrich@geo.uni-goettingen.de

R. Dohrmann

Bundesanstalt für Geowissenschaften und Rohstoffe, Stilleweg 2, 30655 Hannover, Germany
}

\section{Introduction}

In most cases the wetting of sandstones leads to volume increases of the material. Numerous deterioration phenomena on stones can be traced back to this physical loading process. The craquele pattern (Fig. 1a); the formation of deep cracks (Fig. 1b); scaling (Fig. 1c); and differential erosion along fabric discontinuities (Fig. 1d) are representative examples of a deterioration that may be significantly influenced by moisture expansion.

Swelling and shrinking can be observed for a large quantity of stones upon exposure humid (or wet)-dry cycles (Weiss et al. 2004) and this has been mostly attributed to the swelling and shrinking to clay minerals (Schuh 1987; De la Calle and Suquet 1988; Snethlage et al. 1995; Jimenez Gonzalez and Scherer 2004; for principles of clay minerals swelling see Dixon and Weed 1989; Moore and Reynolds 1997; Graf v. Reichenbach and Beyer 1995). In many cases, the studies do not specify exactly under what conditions the swelling of these stones was measured, whether they were the result of changes in the relative humidity $(\mathrm{RH})$ or whether they resulted from total immersion in water. Most of the studies deal with total immersion conditions and the result was misnamed hygric expansion. To avoid the resulting confusion, and to differentiate the conditions that lead to the observed expansion, it was suggested by Delgado Rodrigues and Charola (1996) to refer to them as hygric (when related to RH changes) and hydric (when related to water immersion) swelling. However, the terms hygric and hydric should not be referred to the mechanism but rather to the condition under which the wetting of the material occurs. Thus, the general term "moisture expansion" will be used to describe the volume change processes that result by either condition. 

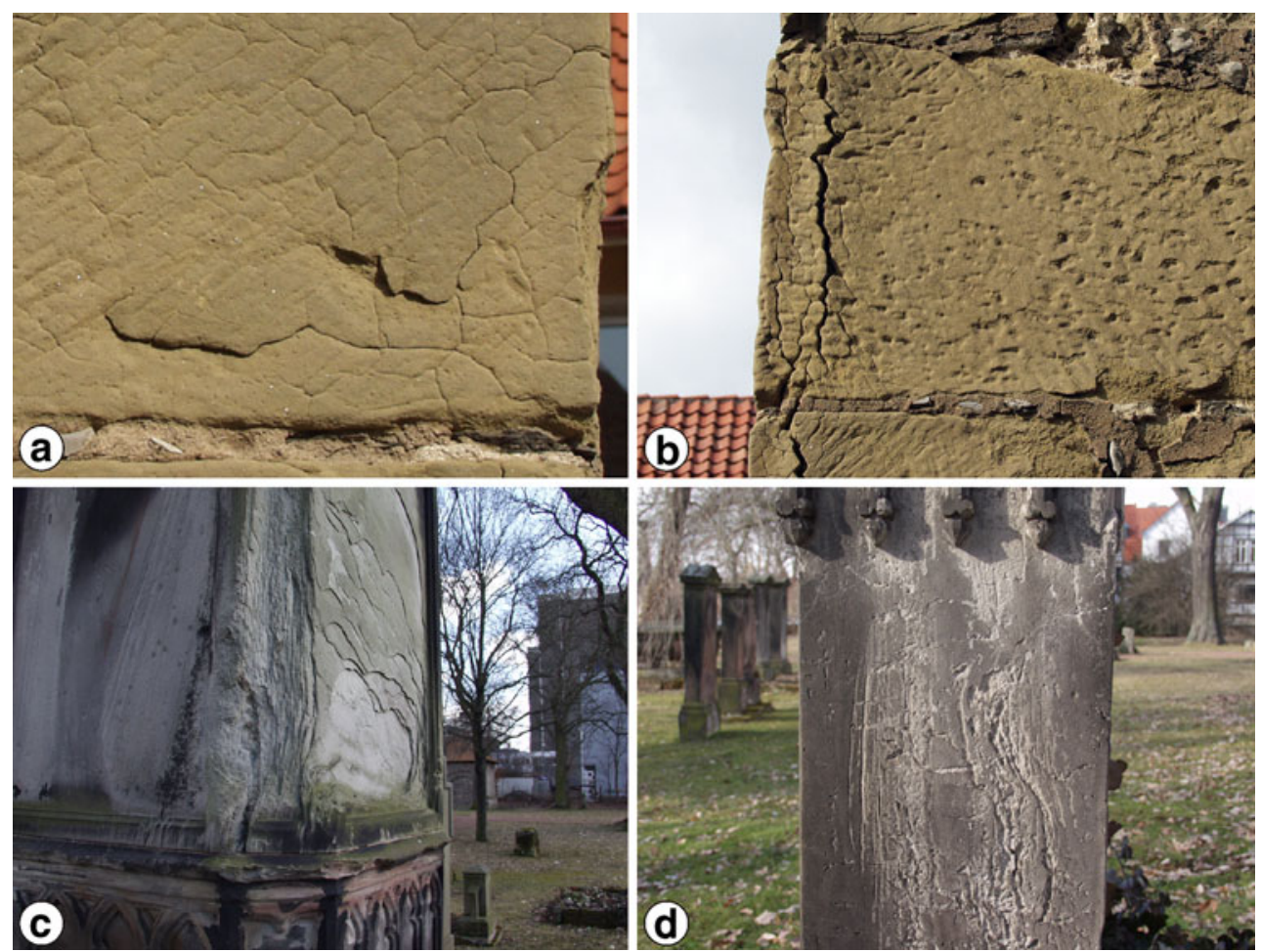

Fig. 1 Different damage phenomena observable in sandstones characterised by a large moisture expansion: $\mathbf{a}, \mathbf{b}$ complex macro-cracking in a litharenitic sandstone (Schilfsandstein Bockenem, Germany),

When clays are present in a stone, two swelling mechanisms are under discussion: (1) intra-crystalline, or simply crystalline; and (2) inter-crystalline, inter-particle or osmotic swelling (Heim 1990; cf. Laird 2006). Crystalline swelling behaviour is related to the specific crystallographic properties of the phyllosilicate minerals. These mainly consist of tetrahedral and octahedral sheets that form thin layers, with a relatively considerable width and length but a negligible thickness. In general, clay minerals can be grouped as minerals with a 1:1 and a 2:1 layer structure. A 1:1 layer means that such structures are built by one tetrahedral and one octahedral sheet. The 2:1 mineral contains one octahedral sheet, which is sandwiched by two tetrahedral sheets. The bonds of the elementary layers are covalent in nature, while the interlayers are characterised by weak ionic bonds. These structural properties are reflected by the cleavage parallel to the basal plane.

A further classification criterion is the composition of the octahedral sheet with respect to the occupation of three crystallographically equivalent sites that have to be filled to compensate the six negative charges. If trivalent cations such as $\mathrm{Al}^{3+}$ are present, one of the three sites remains empty and the minerals are called dioctahedral. This opens another classification criterion, the vacant site can either be on a "pseudo-mirror plane" or not. When divalent cations such as $\mathrm{Mg}^{2+}$ are present, all three positions can be c scaling of a strongly layered sublitharenite and d local backweathering along of fabric discontinuities (Buntsandstein Göttingen, Germany)

occupied leading to the group of trioctahedral minerals. Some clay minerals have isomorphous substitutions in one or both types of sheets, which usually results in an excess negative charge called "layer charge". These charges are compensated by cations, which are either fixed, as the interlayer-potassium in case of illite, or exchangeable, as in the case of smectite. If cations are exchangeable, they can be exchanged by any competing cation present in pore water solution. If the layer charge density is intermediate (between 0.2 and 0.6 charges per formula unit), these cations have a relatively large mobility and are surrounded by varying amounts of hydration water as is the case for smectites. If the charge is close to zero (e.g., kaolinite) no interlayer cations can occur. If the charge is larger than 0.6 but smaller than 0.9 charges per formula unit (e.g., illite and vermiculite), the cation mobility is very limited (e.g., vermiculite). Exchangeable cations can also occupy positions in the interlayer region where water is totally desorbed resulting in collapsed interlayer regions. In illitic interlayer regions, for example, no exchange of potassium versus competing cations in the electrolyte surrounding the clay minerals is possible. In nature, crystallochemical occupation of the structural units is often imperfect and the variety of chemical compositions within single clay minerals such as illites is very large. Chlorites have a 2:1 structure with an additional "polymerised" octahedral 
sheet between two 2:1 units. Both octahedral sheets can differ with respect to cation occupation, which opens room for several different chlorite minerals, all of them without cation exchange capability in the interlayer region.

The most important clay minerals in sedimentary rocks are kaolinite (1:1, dioctahedral), illite (2:1 dioctahedral), chlorite $(2: 1$, variable with respect to di/trioctahedral composition), montmorillonite (2:1, dioctahedral, mineral of the smectite group) and mixed layers. The latter result when clay minerals are stacked on each other in variable amounts and with variable degrees of ordering. Interlayer spaces of mixed layer minerals can be swellable when exposed to water; in this case they behave as "smectitic", although non-swellable mixed layers also exist.

Crystalline swelling of smectites is caused by hydration of the interlayer cations. This is the result of either an increased water vapour partial pressure, i.e., higher $\mathrm{RH}$, or a decrease in electrolytic concentration of the pore water. The hydration occurs in steps with one, two, three and four water layers (Fig. 2a).

A mechanical restraint of the volume expansion results in a swelling pressure. Because of the frequency and large volume variability of the interlayers in the $2: 1$ clay minerals, a considerable volume expansion results when moisture is present. The respective swelling pressure for clays or clay rocks can be calculated from the water sorption isotherm (Kahr 1986; Madsen 1976). In the case of montmorillonite, a swelling pressure of $400 \mathrm{MPa}$ for the first, $110 \mathrm{MPa}$ for the second and $27 \mathrm{MPa}$ for the fourth water layer may result (Madsen and Müller-Vonmoos 1988). The pressures resulting from crystalline swelling are significantly higher than those produced by osmotic swelling discussed below (Heim 1990).

Due to the distinct negative surface charge of the clay mineral, contact with an electrolyte solution leads to the formation of an electrical double layer (Figs. 2b, 3a). Thus, clay minerals are subjected to the typical interactions described by the DLVO theory (Fig. 3b). The main swelling of the clay mineral aggregates can be attributed to the large difference of ionic concentration between the clay mineral surface and the pore solution. The pore solution is defined as the solution that starts at the diffuse ionic double layer. This boundary layer is determined by the potential of the negative loaded clay mineral surface. The pore solution
Fig. 2 Crystalline and osmotic swelling of clay minerals: a crystalline swelling results in the widening of interlayers of swellable clay minerals by hydration of cations (after Madsen and Müller-Vonmoos 1988) and b expansion of neighbour clay particles by osmotic pressure (Heim 1990). c Sketch of disjoining pressure shown for comparison (Butt et al. 2003)
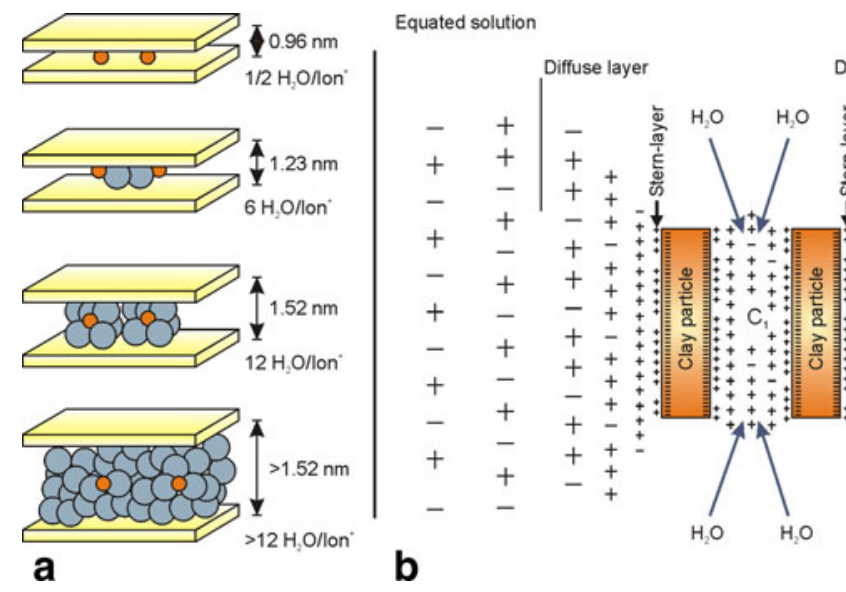

b

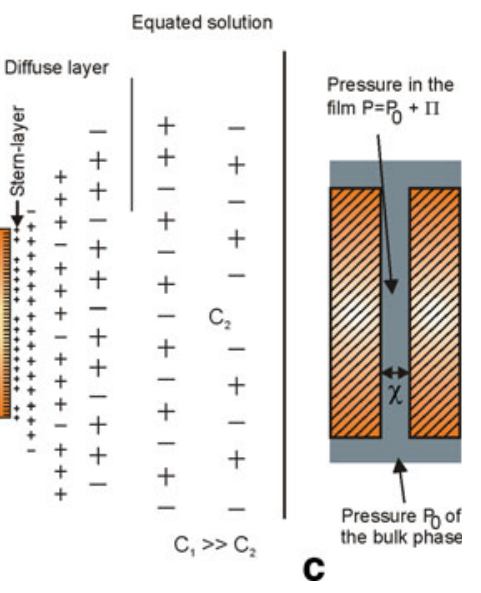

Fig. 3 Configuration of a the hydrate coverage at clay surfaces (Yariv and Cross 1979) and $\mathbf{b}$ interactions between colloidal particles after the DLVO-theory: electrostatic repulsion (GR), van der Waalsattraction (GA) and Born repulsion $(\mathrm{GB}$, with direct particle contact). Black curve represents the entire interaction curve $(\mathrm{GT}=\mathrm{GR}+\mathrm{GA})$ with a primary and secondary minimum (from Lagaly 1997)
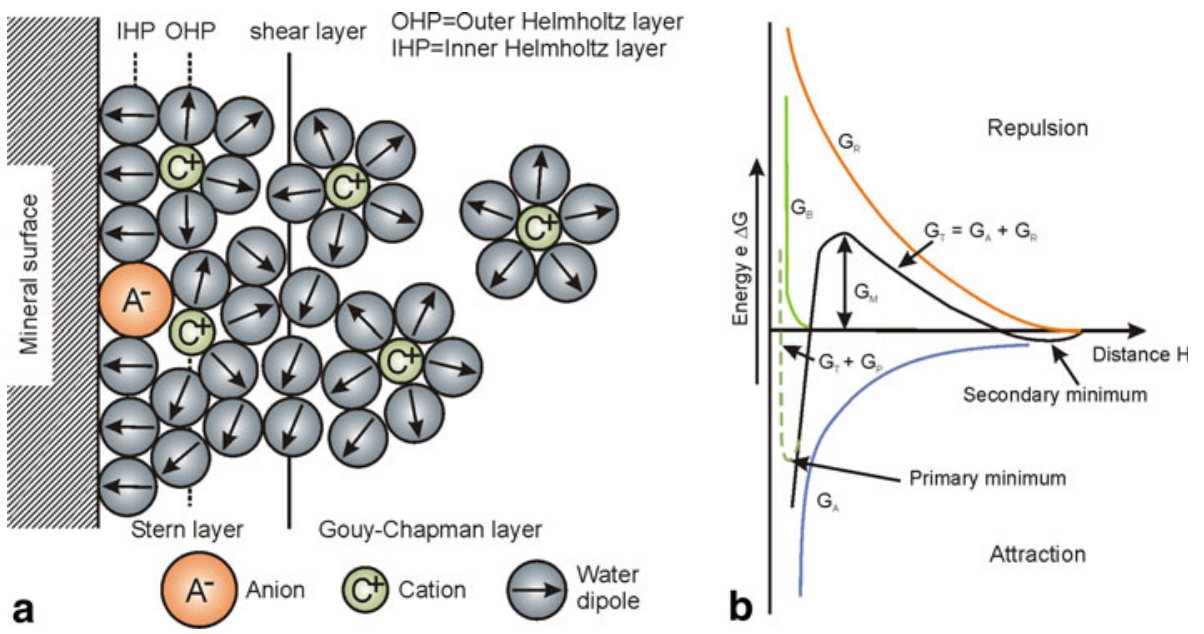
begins when the potential is near zero. The extent of the pore solution depends on the electrolyte concentration. With increasing electrolyte concentration, the double layer is compressed and closer to the mineral surface (MüllerVonmoos and Kohler 1993; Jasmund and Lagaly 1993; Heim 1990).

The water with lower electrolyte concentration has the effect of balancing the concentration (Fig. 2b). Consequently, water is taken up by osmosis between the mineral particles thus pushing them apart. This process is known as "osmotic swelling" (e.g., Gründer 1980; Madsen and Müller-Vonmoos 1989). Water will continue to be suctioned between the clay mineral aggregates until the concentration between the particles is equal to that around them. The intensity of osmotic swelling mainly depends on the mineral surface loading and all clay minerals are subject to this process. However, it is significantly lower than crystalline swelling.

However, there are other mechanisms that can induce swelling in the stone even when clay minerals are not present. This has been attributed to a disjoining pressure (cf. Weimann 2001) that would be the main cause for moisture expansion evident in rocks such as granite and marble, which are clay-poor or -free (Schult and Shi 1996; Weiss 1992).

The term "disjoining pressure" was introduced by Derjaguin and Obukov (1936). Disjoining pressure, $\Pi$, is equal to the difference between the pressure in the film between two surfaces and the pressure in the bulk phase (Fig. 2c). It is defined as the change in the Gibbs free energy with distance per unit area at constant cross sectional area, temperature and volume (cf. Butt et al. 2003). Weimann (2001) described the disjoining pressure during moisture changes and its interaction in the electrical double layer. A reversible increase of the coating thickness due to the adsorption of multi-molecular water layers leads to a decrease of the van der Waals energy. The decreasing attraction energy may result in a repulsion of adjacent particles (Splittgerber 1976; Stockhausen 1981; Weimann 2001). The effect of the disjoining pressure is relevant for all minerals. However, significant swelling would only occur for rocks with a high amount of micropores, i.e., smaller than $0.1 \mu \mathrm{m}$.

Although the processes of disjoining pressure and osmotic swelling are discussed separately in the literature, the principal cause for both is the same. Therefore, the electrolytic concentration of a solution contributes significantly in both processes, because of interaction changes within the double layer. With increasing electrolytic concentration, the diffuse ionic double layer is compressed and electrostatic repulsion will be active at smaller particle displacements but the repulsion effect will strongly increase outwards. In contrast to the electrostatic repulsion, the almost electrolytic independent van der Waals attraction behaves contrariwise. At large particle distances, van der Waals forces are pronouncedly smaller than electrostatic repulsion. However, at small distances the repulsion can be completely overcome by van der Waals forces (Jasmund and Lagaly 1993).

Pronounced moisture length changes by hydric wetting with values up to $20 \mathrm{~mm} / \mathrm{m}$ were observed for mudstones (Madsen 1976; Madsen and Nüesch 1990). For sandstones maximum values of around $5 \mathrm{~mm} / \mathrm{m}$ were detected by Schuh (1987) and Snethlage and Wendler (1997). Experimental investigations on small samples in the laboratory show that moisture expansion at a few loading cycles is a reversible process. This means that by returning to the initial moisture content no permanent residual strain remains, and therefore, no damages are visually evident.

Currently, data on long-term loading cycles as a function of moisture changes are still lacking. Volume changes not only occur by direct wetting, but also with changes of RH (hygric). These volume changes are generally less significant as compared to direct wetting (Steindlberger 2004) but they could be of importance in long term cycling, as occurs in nature. The moisture expansion at high $\mathrm{RH}$ ranges strongly depends on the material. Blöchl et al. (1998) measured expansion increases between 10 and 28\% for three different types of sandstones conditioned at $95 \%$ RH. Ruedrich et al. (2005) have shown that values close to $80 \%$ of the total moisture expansion can be obtained in this humidity range.

The main goal of the present study was to acquire more information on the expansion processes in sandstones due to moisture uptake. The study focussed on determining to what extent the grain fabric and the pore space properties might be responsible for the moisture expansion of sandstones. Eight sandstones, characterised by varying mineralogical compositions and fabric properties, were selected for the study.

The mineralogical investigations focussed mainly on the content of swellable clay minerals. X-ray diffraction (XRD) measurements were conducted on the grain size fraction of $<2 \mu \mathrm{m}$. In addition, the cation exchange capacity (CEC), an indicator for the presence of expansive clay minerals, was determined on both bulk samples and different grain size fractions. For the quantification of the grain fabric (grain size and grain shape) image analyses were performed. Furthermore, petrophysical parameters of the pore space were determined, such as the porosity and pore radii distribution, the water transport and retention properties (capillary water uptake, water diffusion resistance and sorption) as well as the tensile strength at dry and water-saturated sample conditions. The expansion and the swelling pressures developed were measured both for water-saturated sample conditions (hydric) and at changing RH situations (hygric). 


\section{Mineralogical composition and rock fabric}

The rock fabric of sandstones controls their petrophysical properties as well as their material behaviour during deterioration. By rock fabric, the grain size, sorting, roundness of detrital grains, grain contacts, and cementing material properties is understood and it is the result of geological processes, i.e., sedimentation, compaction, diagenesis and post-diagenetic alteration. The selected sandstones for this study originate from geological periods between the Carboniferous and the Cretaceous and are characterised by a large fabric variety. Fabric analyses were performed under polarised light microscopy of standard thin sections to characterise the different grain parameters, such as mineralogical composition, properties of detrital, and authigenic components. Quantitative image analyses were carried out to determine the grain size and preferred grain boundary orientation. The mineralogical composition was complemented by X-ray diffraction analysis. Information concerning the clay mineral content was obtained by determining the CEC. The results of these analyses are reported in Table 1.

\section{Grain fabric}

Based on the grain fabric the investigated sandstones can be divided into three groups. The first group, constituted by the Obernkirchen, Bebertal and Uder sandstones, are characterised by a high fraction of quartz grains. The Obernkirchen and Uder sandstones are well sorted and can be described as quartz-arenites, whereas the Bebertal sandstone has a higher content of lithoclasts and is classified as a sublitharenite. The first group shows a low matrix and cement content. Furthermore, a low compaction is evidenced by pointed and longitudinal grain contacts. The sandstones are also characterised by well rounded detrital grains.

The second group comprises the sandstones from Sand and Schleerieth. They show a relatively high content of lithoclasts, and thus, these rocks can be classified after McBride (1963) as litharenites. Although a high proportion of matrix minerals are present, cementing material is not frequent. The rocks can be further characterised by a slight sedimentary compaction as compared to the first group. The grain contacts are mostly located at points or are longitudinal.

The third group comprises the sandstones from Karlshafen, Lobach and Tambach that can be described as sublitharenites. They exhibit a mineral composition of detrital grains between the first and the second group. The interstitial spaces between the coarser detrital grains are mostly filled with matrix minerals and cement. The sandstone from Karlshafen shows the highest content of matrix minerals. Cements consist mostly of quartz. The Karlshafen and Lobach sandstones have the highest compaction of all the studied sandstones. Detrital components are poorly rounded and frequently angular. Only the Tambach sandstone exhibits some medium and rounded grains. This sandstone shows further the strongest cementation by quartz growth fringes.

\section{Grain size distribution}

The medium grain size of the investigated sandstones varies between $0.071 \mathrm{~mm}$ for the Obernkirchen and $0.219 \mathrm{~mm}$ for the Uder sandstone (Table 1). The grain sizes determined by quantitative fabric analysis are generally smaller than those determined by granulometric analysis. This can be attributed to the cut-effect of the thin sections.

Sandstone samples from Obernkirchen and Uder exhibit a well-sorted grain fabric. The grain size spectrum of the Obernkirchen sandstone covers the range between coarse silt and fine sand. Uder is coarser grained. Both sandstones show a more or less Gaussian grain size distribution. Sandstones from Schleerieth and Sand show a comparable distribution pattern, but their grain size distribution ranges between coarse silt and medium sand. The Tambach sandstone shows the same grain sizes as the first group but is characterised by a poor sorting. The sandstone from Uder has the largest grain size with a mean value of around $0.2 \mathrm{~mm}$. The poorly sorted Bebertal sandstone exhibits the most expanded grain spectrum of the investigated sandstones, from 0.05 to $0.50 \mathrm{~mm}$.

\section{Grain shape orientation}

All investigated sandstones show a preferred grain orientation parallel to the $X$-direction in the $X Z$-plane (Fig. 4). The intensity of this anisotropy varies from strong to weak in the following order: Schleerieth, Karlshafen, Tambach, Sand, Uder, Lobach, Bebertal, and Obernkirchen. All sandstones, except the Uder one, exhibit no preferred grain orientation parallel to the $X$-direction in the $X Y$-plane (the bedding plane), and thus are characterised by a pancake fabric (oblate). The Uder sandstone is the only one to show a preferred grain orientation parallel to the $X$-direction in the $X Y$-plane resulting in a cigar-shaped fabric (prolate).

\section{Mineral content}

The clay mineral composition of the sandstones was determined by X-ray diffraction (XRD) (Table 1; Fig. 5). All sandstones are mainly composed of quartz. The rock from Obernkirchen shows the highest quartz content and the lowest feldspar content. Chlorite is a main component 


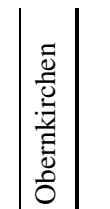

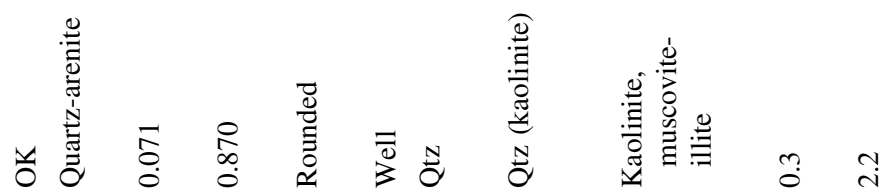

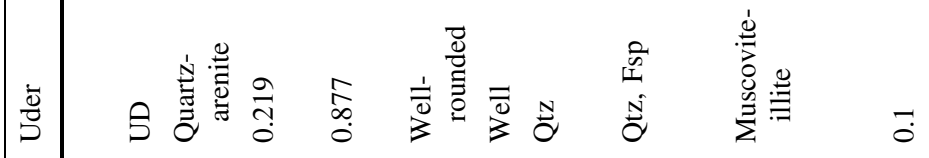

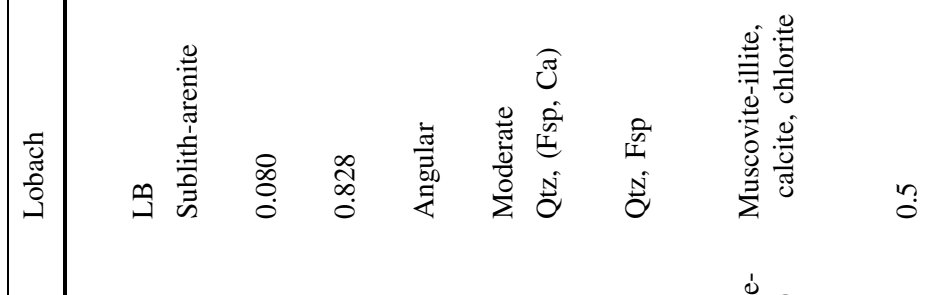

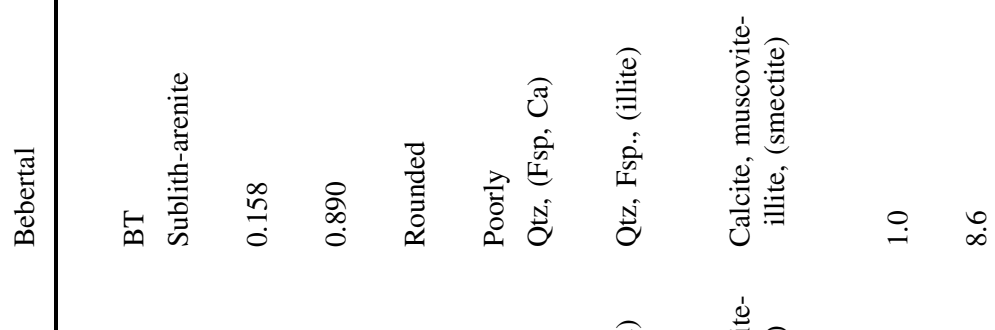

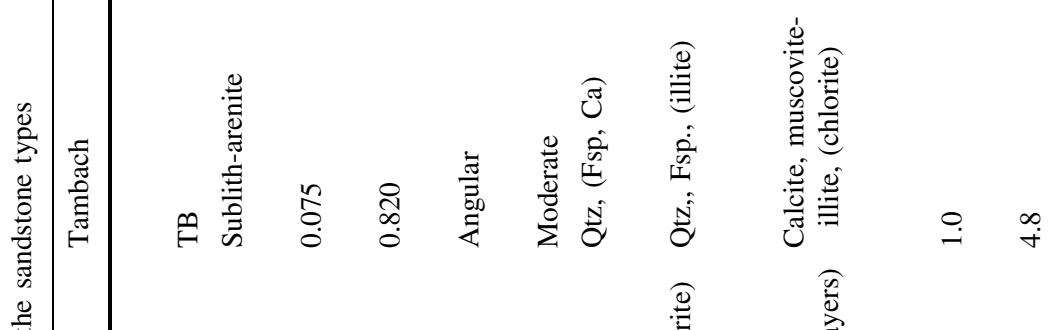

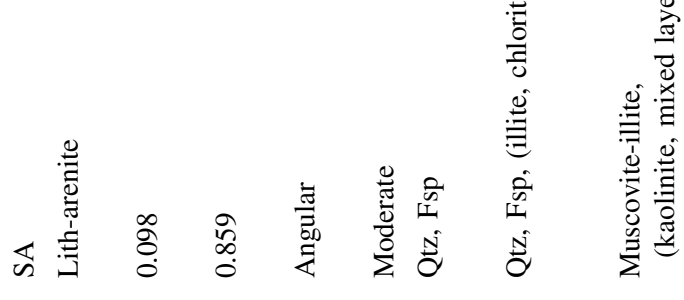

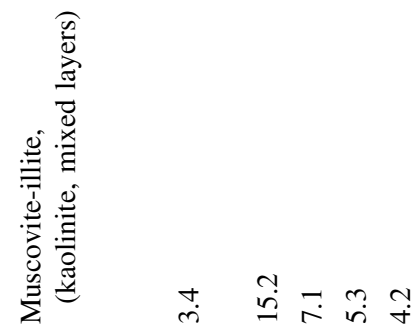

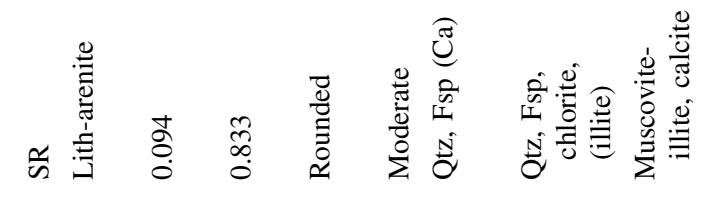

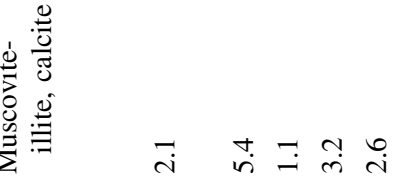

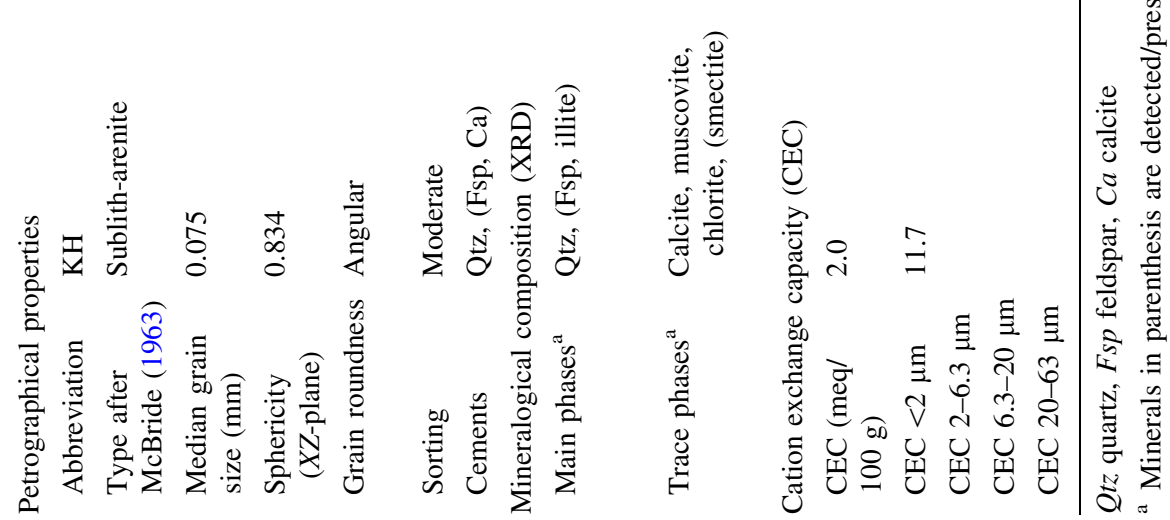


Fig. 4 Thin section photomicrographs and the main grain parameters of all sandstones. Left crossed polarisers; top right preferred grain boundary orientation in the $X Y$ (parallel bedding) and $X Z$-plane, bottom right grain size distribution ( $n$ number of analysed grains, $A$ analysed area)
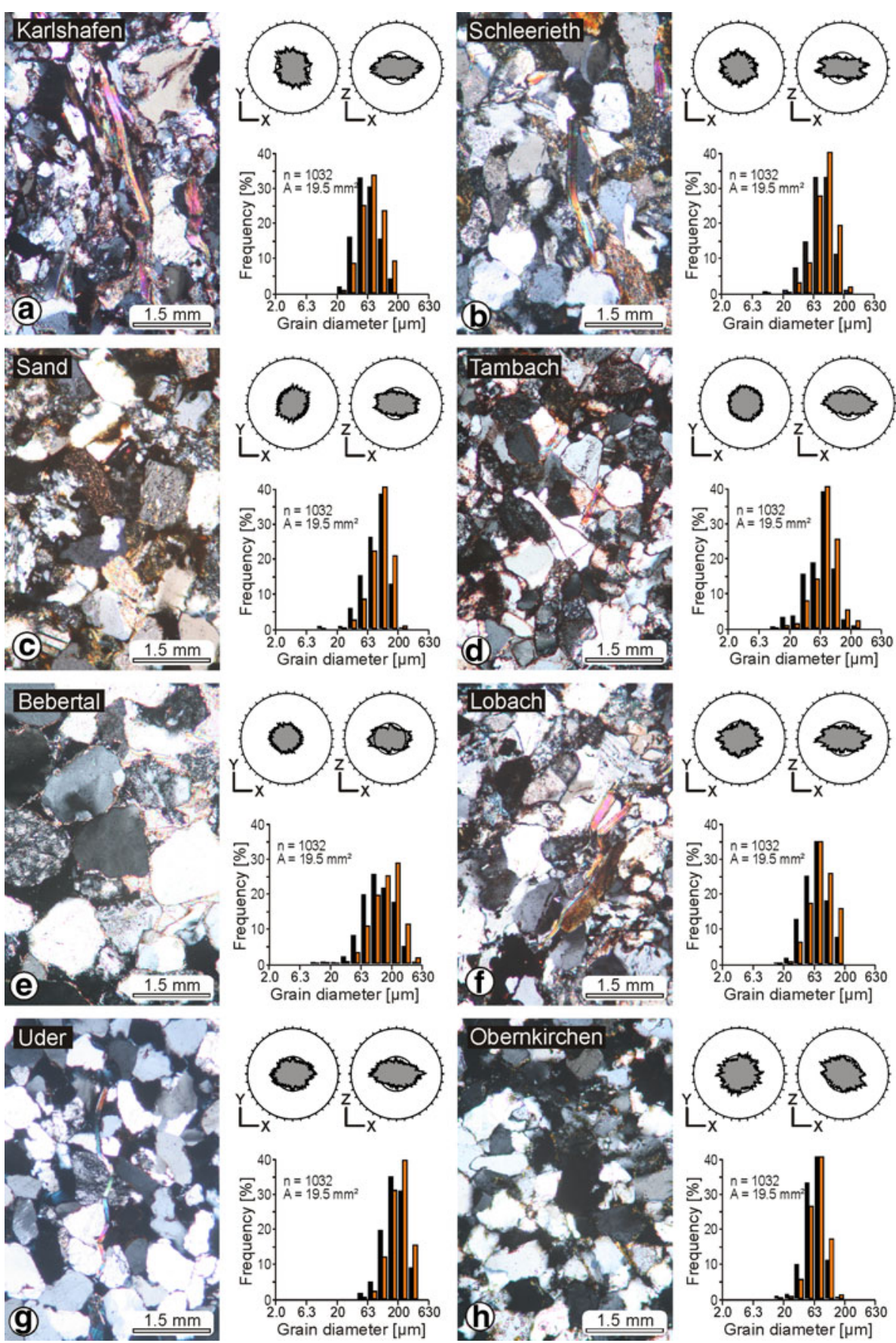

in the Schleerieth sandstone and was also detected in trace amounts in the Sand, Tambach and Karlshafen samples. The rocks from Tambach, Bebertal, Karlshafen and Schleerieth contain calcite as an accessory mineral phase, which occurs as cement in the rock fabric. Samples from Obernkirchen, Karlshafen and Sand contain low contents of kaolinite. For the latter sandstone the content is close to the detection limit of the XRD. Furthermore, muscoviteillite is detectable as a trace element in all samples.

Swellable clay minerals were only found in the samples from Sand, Karlshafen and Bebertal. The contents are very low. The sandstones from Karlshafen and Bebertal contain smectite (Fig. 5). The Schleerieth sample exhibits swellable clay minerals in the form of interlayer structures.

Further information on the clay minerals was obtained from measuring the CEC using the cupric-triethylentetramine method (Dohrmann and Kaufhold 2009, modified after Meier and Kahr 1999). The CEC values support the XRD results (Table 1; Fig. 5). The clays in the Sand sample exhibit the highest CEC, compared to the other sandstones. In contrast, the Oberkirchen sandstone contains clay minerals (kaolinite) characterised by a low CEC. 
Fig. 5 XRD of clay fractions of sandstones after ethylene glycol solvation. Intensities are shifted for better differentiation. From bottom to top Obernkirchen, Bebertal, Tambach, Sand, Schleerieth, Karlshafen (Uder and Lobach: no clay fraction available)

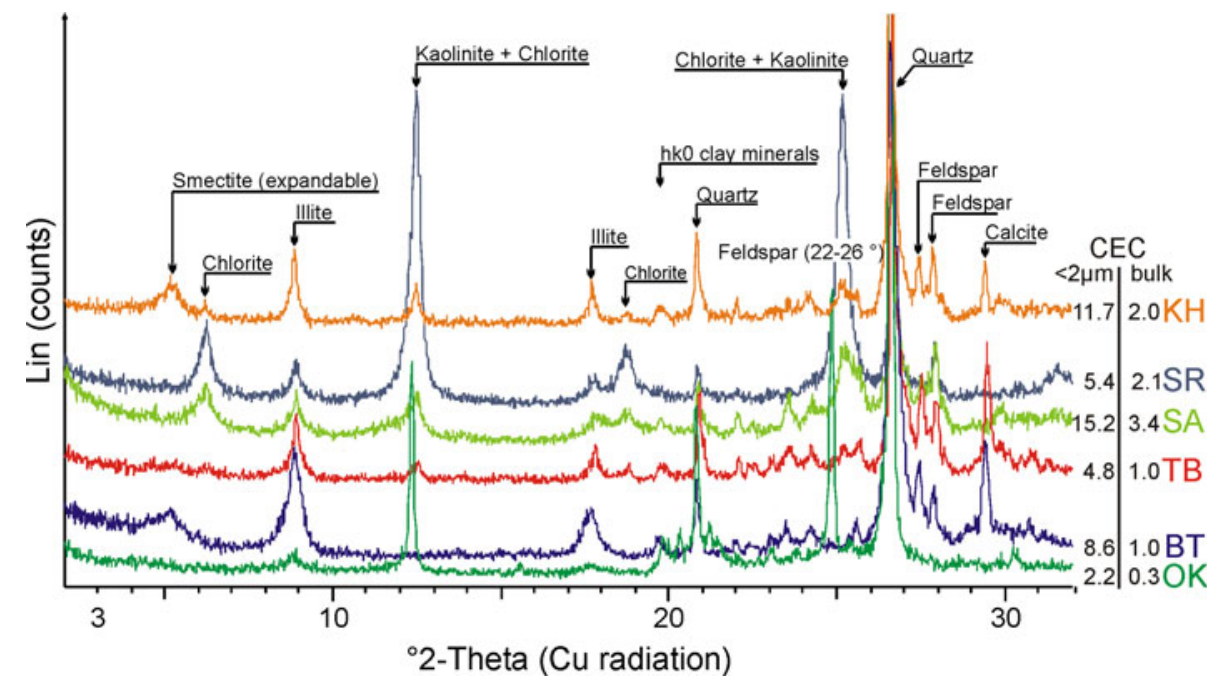

Table 2 Pore space properties, moisture transport, and retention properties of the different sandstones

\begin{tabular}{|c|c|c|c|c|c|c|c|c|}
\hline Sandstone type & Karlshafen & Schleerieth & Sand & Tambach & Bebertal & Lobach & Uder & Obernkirchen \\
\hline Effective porosity (vol.\%) & 4.64 & 14.95 & 15.41 & 8.28 & 9.68 & 11.94 & 23.26 & 19.90 \\
\hline Matrix density $\left(\mathrm{g} / \mathrm{cm}^{3}\right)$ & 2.69 & 2.70 & 2.68 & 2.65 & 2.65 & 2.69 & 2.65 & 2.65 \\
\hline Bulk density $\left(\mathrm{g} / \mathrm{cm}^{3}\right)$ & 2.56 & 2.30 & 2.27 & 2.43 & 2.39 & 2.37 & 2.03 & 2.12 \\
\hline Average pore radius $(\mu \mathrm{m})$ & 0.088 & 0.105 & 0.175 & 0.192 & 0.387 & 0.269 & 5.374 & 2.011 \\
\hline Absolute micropore porosity (\%) & 2.73 & 6.44 & 6.46 & 3.45 & 2.17 & 2.72 & 1.86 & 2.50 \\
\hline Average pore radius micro pores $(\mu \mathrm{m})$ & 0.027 & 0.024 & 0.026 & 0.023 & 0.022 & 0.029 & 0.015 & 0.018 \\
\hline \multicolumn{9}{|l|}{$w$ value $\left(\mathrm{kg} / \mathrm{m}^{2} \sqrt{\mathrm{h}}\right)$} \\
\hline$X$ & 0.3 & 1.8 & 2.0 & 0.5 & 1.3 & 1.1 & 23.5 & 2.9 \\
\hline$Z$ & 0.5 & 1.9 & 1.9 & 0.6 & 0.9 & 1.4 & 19.8 & 2.6 \\
\hline$A(\%)$ & 35 & 6 & 7 & 20 & 25 & 19 & 16 & 9 \\
\hline \multicolumn{9}{|l|}{$\mu$ value } \\
\hline$X$ & 48 & 22 & 23 & 38 & 31 & 39 & 13 & 18 \\
\hline$Y$ & 45 & 25 & 22 & 33 & 31 & 32 & 12 & 21 \\
\hline$Z$ & 61 & 26 & 28 & 29 & 32 & 43 & 14 & 18 \\
\hline$A(\%)$ & 27 & 15 & 21 & 23 & 4 & 24 & 12 & 15 \\
\hline$S$ value & 0.83 & 0.79 & 0.76 & 0.66 & 0.68 & 0.68 & 0.60 & 0.69 \\
\hline
\end{tabular}

\section{Petrophysical properties}

\section{Porosity}

To characterise the open (effective) porosity, hydrostatic weighing was performed on cubic samples $(65 \times 65 \times$ $65 \mathrm{~mm}$ ). To calculate the porosity, the water-saturated mass and the buoyancy mass of the vacuum water saturated sample as well as the dry sample mass were used. The open porosity values cover a wide spectrum, from 4.64 to $23.26 \%$ (Table 2). The selected sandstones can be subdivided into three groups: low $(<10 \%)$, medium $(10-20 \%)$, and high porosity $(>20 \%)$. The latter group includes the sandstones from Obernkirchen and Uder. Samples from
Lobach, Sand, and Schleerieth show medium porosity, whereas the Karlshafen Bebertal and Tambach sandstones have low porosity.

Pore radii distribution

The pore size distribution of the samples was determined by mercury porosimetry (cf. van Brakel et al. 1981). Based on the pore size distribution pattern, the sandstones can be divided into three types (cf. Ruedrich and Siegesmund 2006). Type A (Uder) shows a narrow spaced pore radii maximum, and therefore the pores are more or less equal in size (Fig. 6g). The other types have a wider pore size distribution. Type B (Obernkirchen, Lobach, Karlshafen 

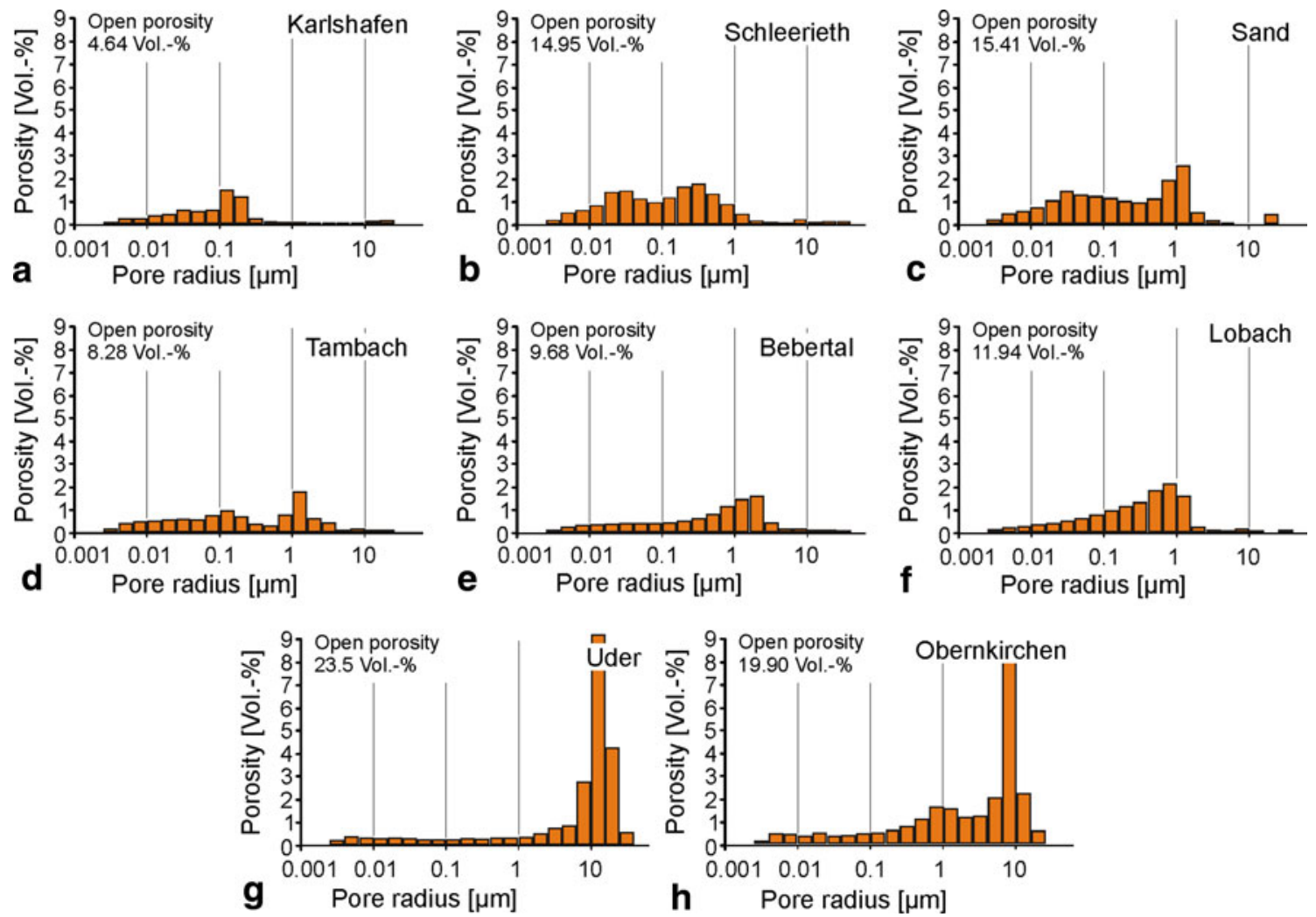

Fig. 6 Pore radii distribution of the investigated sandstones

and Bebertal) exhibits a wide range of pore radii with one maximum, i.e., a unimodal distribution (Fig. 6a, e, f, h). In contrast, Type C (Schleerieth, Sand and Tambach) is characterised by a second maximum of smaller pores and can be described as bimodal (Fig. 6b-d).

From the pore radii distribution, the average pore radius was calculated. For this purpose, the pore radii classes were weighted according to their contribution to the total porosity. The values vary between $0.088 \mu \mathrm{m}$ for the Karlshafen sample and $5.374 \mu \mathrm{m}$ for the Uder sandstone. For the average pore radius a good connection with the porosity of the respective rock exists (Table 2). The sample with the highest porosity also exhibits the highest average pore radius and vice versa.

Micropores were evaluated in greater detail because the disjoining pressure can only develop in these smaller pores. The total volume of micropore radius smaller than $0.1 \mu \mathrm{m}$ was calculated and is given in Table 2. The highest micropore content with $6.46 \%$ can be found in the sandstone from Sand and the lowest value with $1.86 \%$ for the Uder sandstone. Furthermore, the average pore radius was calculated also for the micropore content. The sandstones with the lowest porosity and lowest microporosity show the smallest average pore radius of micropores.
Capillary water absorption

The directional dependence of capillary water absorption was measured on sample cubes $(65 \times 65 \times 65 \mathrm{~mm})$ prepared according to the three principal directions $(X, Y, Z)$. Thus, directionally dependent measurements could be performed at the same sample. Specimens were set with the bottom plane into $0.3 \mathrm{~cm}$ water and the weight increase over time was measured. The calculated water absorption coefficients ( $w$ value) are given in Table 2 for the $X$ - and Zdirections. The $w$ value of the sandstones varies between $23.5 \mathrm{~kg} / \mathrm{m}^{2} \sqrt{ } \mathrm{h}$ for the Uder and $0.3 \mathrm{~kg} / \mathrm{m}^{2} \sqrt{ } \mathrm{h}$ for the Karlshafen sandstone. For most of the studied sandstones a pronounced directional dependence was observed with the anisotropy varying between 6 and 35\%.

\section{Water vapour diffusion}

Apart from capillary absorption, the diffusion of water vapour is the second most important water transport mechanism in porous materials. The water vapour diffusion resistance value $(\mu)$ of the sandstones was measured using the wet-cup method. This parameter characterises the diffusion resistance of a porous material compared to an equally dimensioned inactive air film. Slices of the stones 
$(\varnothing 40 \times 10 \mathrm{~mm})$ were attached as covers on Teflon cups that held liquid water $(100 \% \mathrm{RH})$ and these were then set into a $50 \%$ RH environment, so that a moisture flow occurred through the porous material. The weight loss of the cups was measured over time and from it the moisture flow through the material could be calculated. The non-dimensional water vapour diffusion resistance value $(\mu)$, varies between 13 for the Uder sandstone in the $X$-direction, parallel to the bedding, to 61 for the Karlshafen sandstone perpendicular to the bedding (Table 2). $\mu$ also shows a strong directional dependence ranging from 4 to $27 \%$.

\section{Sorption and saturation degree}

Hygroscopic water sorption was measured between 15 and $95 \%$ RH. The measurements were carried out on drilling core slices with a diameter and thickness of $\varnothing 20 \times 100 \mathrm{~mm}$, respectively. The amount of adsorbed water was converted to "saturation degree" at the different humidity stages with respect to the total water absorption under vacuum of the respective samples. The pattern of water sorption is comparable for all sandstones. Between 15 and $75 \% \mathrm{RH}$, a fairly linear weight increase is observable (Fig. 7). However, upon reaching 75\% $\mathrm{RH}$ and higher RH, the weight increases significantly. Sandstones with the largest pore spaces, such as Uder and Obernkirchen exhibit the lowest weight increase over the whole humidity spectrum. The behaviour of the Lobach and Bebertal sandstones is comparable but the weight increase is slightly higher. The highest sorption is shown by the samples from Karlshafen, Tambach, Schleerieth and Sand, that have the highest number of micropores.

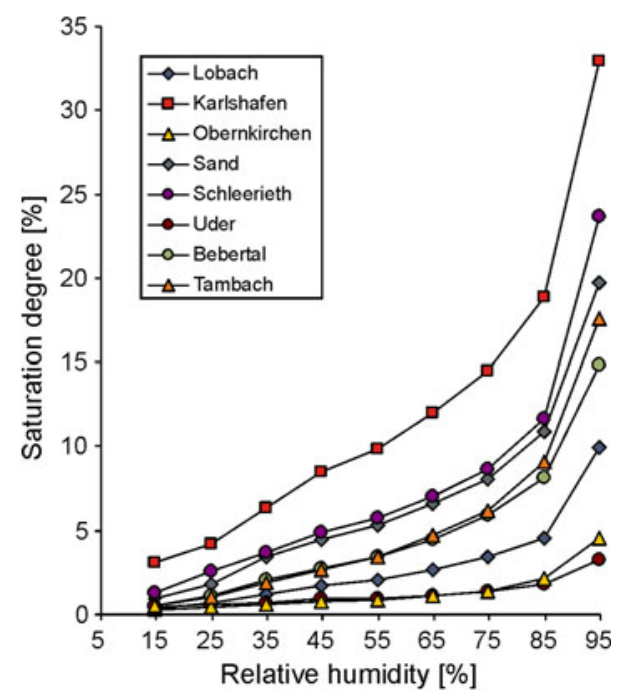

Fig. 7 Degree of saturation in the sandstones as a function of relative humidity
These sandstones also show the highest saturation degrees at $95 \%$ RH. The highest saturation degree is observable with $34 \%$ for the Karlshafen sandstone. The lowest saturation at $95 \% \mathrm{RH}$ is shown by the sandstone from Uder with around $3 \%$ (Fig. 7).

Additionally saturation degree ( $S$ value) was also calculated from the maximum water absorption obtained by 24-h total water immersion over that corresponding to the water saturation under vacuum. The saturation degrees of most samples varied between 0.60 and 0.80 (Table 2). Only the sandstone from Karlshafen exhibits a slightly larger $S$ value of 0.83 .

Tensile strength

The tensile strength $\left(\sigma_{z}\right)$ was determined by means of the "Brazilian test", which involves disc-shaped specimens. The samples were $40 \mathrm{~mm}$ in diameter and $40 \mathrm{~mm}$ in length. In order to calculate the average value, a minimum of four samples was used. A constant strain rate of $0.3 \times 10^{-6} \mathrm{~mm} \mathrm{~s}^{-1}\left(\approx 10-5 \mathrm{~s}^{-1}\right)$ was applied. The tensile strength was measured perpendicular to the $X Y$ - and $X Z$ plane, where $X Y$ is the bedding plane. The resistance of sandstones against tensile stresses is an important parameter for all physical weathering processes, because the induced stresses have to exceed the tensile strength for damage to occur. As wet sandstones have a lower strength than dry sandstones, the tensile strength at both dry and water-saturated conditions was measured. The results are reported in Table 3. The tensile strength is in general higher in the parallel to bedding direction for either condition. However, the Obernkirchen sandstone has a higher tensile strength in the perpendicular to bedding direction when saturated in water. All the values vary between $3.3 \mathrm{~N} / \mathrm{mm}^{2}$ for the sandstone from Uder (perpendicular to bedding) and $13.3 \mathrm{~N} / \mathrm{mm}^{2}$ (parallel to bedding) for the Tambach one, under dry condition. These sandstones also showed equivalent extreme values under water-saturated conditions, $2.3 \mathrm{~N} / \mathrm{mm}^{2}$ (perpendicular to bedding) for the Uder and $7.6 \mathrm{~N} / \mathrm{mm}^{2}$ (parallel to bedding) for the Tambach sandstone. The tensile strength reduction by water saturation is severe, $57 \%$ for the Schleerieth sandstone and $30 \%$ for the Uder sample.

\section{Compressive strength and Young's modulus}

For the compressive strength $\left(\sigma_{\mathrm{UCS}}\right)$ measurements on standard specimens of $50 \mathrm{~mm}$ in diameter and $50 \mathrm{~mm}$ in length with coplanar end-faces were performed (with an accuracy of $0.1 \#$ ). The load was applied to the end-faces of the specimen with a strain rate of $1,000 \mathrm{~N} / \mathrm{s}$ until failure. The maximum load is defined as the uniaxial compressive strength. The Young's modulus was determined from the 
Table 3 Tensile strength in dry and water-saturated conditions and the respective strength reduction as well as the compressive strength, the elastic modulus and the swelling pressure

\begin{tabular}{|c|c|c|c|c|c|c|c|c|c|}
\hline Sandstone type & $\begin{array}{l}\text { Direction/ } \\
\text { Anisotropy }\end{array}$ & Karlshafen & Schleerieth & Sand & Tambach & Bebertal & Lobach & Uder & Obernkirchen \\
\hline \multirow[t]{3}{*}{ Tensile strength dry $\left(\mathrm{N} / \mathrm{mm}^{2}\right)$} & $Y$ & 9.2 & 6.9 & 6.8 & 13.3 & 6.2 & 5.2 & 4.2 & 5.9 \\
\hline & $Z$ & 6.4 & 6.8 & 4.7 & 9.7 & 5.2 & 4.2 & 3.3 & 5.5 \\
\hline & $A(\%)$ & 30 & 2 & 31 & 27 & 17 & 7 & 22 & 7 \\
\hline \multirow{3}{*}{$\begin{array}{l}\text { Tensile strength water saturated (N/ } \\
\left.\mathrm{mm}^{2}\right)\end{array}$} & $Y$ & 5.2 & 2.9 & 3.4 & 7.6 & 4.3 & 3.5 & 2.9 & 3.6 \\
\hline & $Z$ & 4.2 & 3.0 & 2.9 & 7.6 & 3.2 & 2.5 & 2.3 & 4.3 \\
\hline & $A(\%)$ & 19 & 5 & 16 & 0 & 26 & 31 & 21 & 15 \\
\hline Tensile strength reduction $(\%)$ & & 39 & 57 & 44 & 33 & 34 & 36 & 30 & 30 \\
\hline \multirow[t]{3}{*}{ Compressive strength $\left(\mathrm{N} / \mathrm{mm}^{2}\right)$} & $Z$ & 108 & 63 & 62 & 145 & 65 & 94 & 47 & 60 \\
\hline & $Y$ & 105 & 51 & 60 & 122 & 67 & 95 & 37 & 78 \\
\hline & $A(\%)$ & 3 & 18 & 4 & 16 & 3 & 1 & 21 & 23 \\
\hline \multirow[t]{3}{*}{ Young's modulus $\left(\mathrm{kN} / \mathrm{mm}^{2}\right)$} & $Z$ & 11 & 7 & 9 & 19 & 10 & 15 & 13 & 12 \\
\hline & $Y$ & 19 & 7 & 8 & 23 & 12 & 13 & 9 & 18 \\
\hline & $A(\%)$ & 40 & 3 & 5 & 15 & 16 & 15 & 32 & 32 \\
\hline \multirow[t]{2}{*}{ Swelling pressure $\left(\mathrm{N} / \mathrm{mm}^{2}\right)$} & $Y$ & 0.072 & 0.068 & 0.068 & 0.032 & 0.044 & 0.032 & 0.016 & 0.020 \\
\hline & $Z$ & 0.100 & 0.084 & 0.084 & 0.064 & 0.068 & 0.064 & 0.028 & 0.032 \\
\hline
\end{tabular}

stress-strain curve of the uniaxial compressive strength test. The results are presented in Table 3.

For the data of the compressive strength a good correlation to the porosity is observable. The highest $\sigma_{\mathrm{UCS}}$ values between $145 \mathrm{~N} / \mathrm{mm}^{2}$ (Z-direction perpendicular to bedding) and $122 \mathrm{~N} / \mathrm{mm}^{2}$ (Y-direction parallel to bedding) is shown by the low porous Tambach sandstone. In contrast, for the high porous Uder sandstone the lowest uniaxial compressive strength is about $40 \mathrm{~N} / \mathrm{mm}^{2}$ (parallel to bedding). The directional dependence between the measurements parallel and perpendicular to the bedding is mostly below $23 \%$.

The Young's modulus of the studied sandstones varies between $7 \mathrm{kN} / \mathrm{mm}^{2}$ for both fabric directions of the Schleerieth sandstone and $23 \mathrm{kN} / \mathrm{mm}^{2}$ parallel to the bedding ( $Y$-direction) of the Tambach sandstone (Table 3). The directional dependence between the measurements parallel and perpendicular to the bedding is mostly below
$32 \%$. Only the strongly layered Karlshafen sandstone exhibits a strong anisotropy of $40 \%$.

\section{Moisture expansion}

The moisture expansion by hygric wetting of the sandstones was determined on cylindrical samples $(\varnothing 20 \mathrm{~mm} \times$ $100 \mathrm{~mm}$ ), which were pre-conditioned at $15 \% \mathrm{RH}$ and a temperature of $30^{\circ} \mathrm{C}$ in a climate chamber at different $\mathrm{RH}$ stages. Expansion measurements by hydric wetting were also performed with the samples under water-saturated conditions. The results are summarised in Table 4.

To measure the swelling by hygric wetting, the samples were placed between a displacement transducer and a support within the climate chamber. The RH was gradually increased from 15 up to $95 \%$. The respective ramps were held until the length change equilibrated, about $24 \mathrm{~h}$ at each RH. For water-saturated conditions, the samples were

Table 4 Hygric expansion depending on relative humidity and water saturation and the differences in percent for the three directions

\begin{tabular}{lcccccccc}
\hline Sandstone type & Karlshafen & Schleerieth & Sand & Tambach & Bebertal & Lobach & Uder & Obernkirchen \\
\hline$X$-95\% & 0.267 & 0.227 & 0.226 & 0.265 & 0.118 & 0.112 & 0.105 & 0.085 \\
$X$-wet & 0.547 & 0.527 & 0.536 & 0.599 & 0.449 & 0.333 & 0.365 & 0.228 \\
X-diff. (\%) & 48.8 & 43.1 & 42.2 & 44.2 & 26.2 & 33.8 & 28.9 & 37.0 \\
Y-95\% & 0.36 & 0.225 & 0.205 & 0.207 & 0.114 & - & 0.088 & 0.088 \\
$Y$-wet & 0.735 & 0.52 & 0.49 & 0.507 & 0.415 & - & 0.288 & 0.243 \\
$Y$-diff. (\%) & 49.0 & 43.3 & 41.8 & 40.8 & 27.5 & - & 30.4 & 36.1 \\
Z-95\% & 0.656 & 0.567 & 0.422 & 0.250 & 0.152 & 0.238 & 0.165 & 0.101 \\
Z-wet & 1.321 & 1.247 & 0.953 & 0.570 & 0.524 & 0.602 & 0.583 & 0.262 \\
Z-diff. (\%) & 49.7 & 45.5 & 44.3 & 43.9 & 29.0 & 39.5 & 28.4 & 38.7 \\
\hline
\end{tabular}




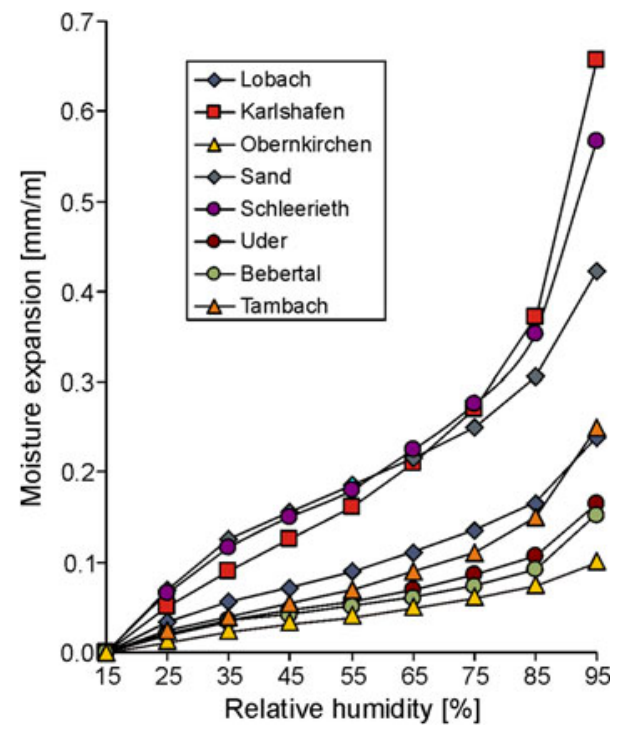

Fig. 8 Moisture expansion depending on relative humidity stages perpendicular to bedding ( $Z$-direction) of the sandstones

completely immersed in distilled water. The resolution of the displacement transducer is $0.1 \mu \mathrm{m}$ and the accuracy is about $0.5 \mu \mathrm{m}$. The measurements were carried out on samples parallel to both the $X$ - and the Z-direction (parallel and perpendicular to bedding, respectively).

Large differences in expansion were measured under water-saturated conditions. The sandstone from Obernkirchen showed the lowest expansion, around $0.24 \mathrm{~mm} / \mathrm{m}$, while all the other samples exhibit swelling higher than $0.3 \mathrm{~mm} / \mathrm{m}$

The expansion suffered by all samples (perpendicular to the bedding) upon changes of RH is shown in Fig. 8. In general, this graph is comparable to the sorption curves shown in Fig. 7. Between 35 and $75 \%$ RH, a fairly linear increase of length is observable. Only above $75 \% \mathrm{RH}$ can a significant change in length be observed. The maximum value of $0.65 \mathrm{~mm} / \mathrm{m}$ was measured for the Karlshafen sample, while the lowest, $0.1 \mathrm{~mm} / \mathrm{m}$ corresponded to the Obernkirchen sandstone.

As is to be expected, all samples at $95 \% \mathrm{RH}$ showed a smaller expansion than when measured saturated in water. The difference in saturation between these two conditions, correlates well with the difference in expansion suffered by these samples as measured perpendicular to the bedding plane, suggesting that there is a single mechanism at work producing the expansion.

\section{Swelling pressure}

If the strain in the samples caused by swelling is mechanically inhibited, a swelling pressure will develop (cf. Kocher 2005). The swelling pressures were measured

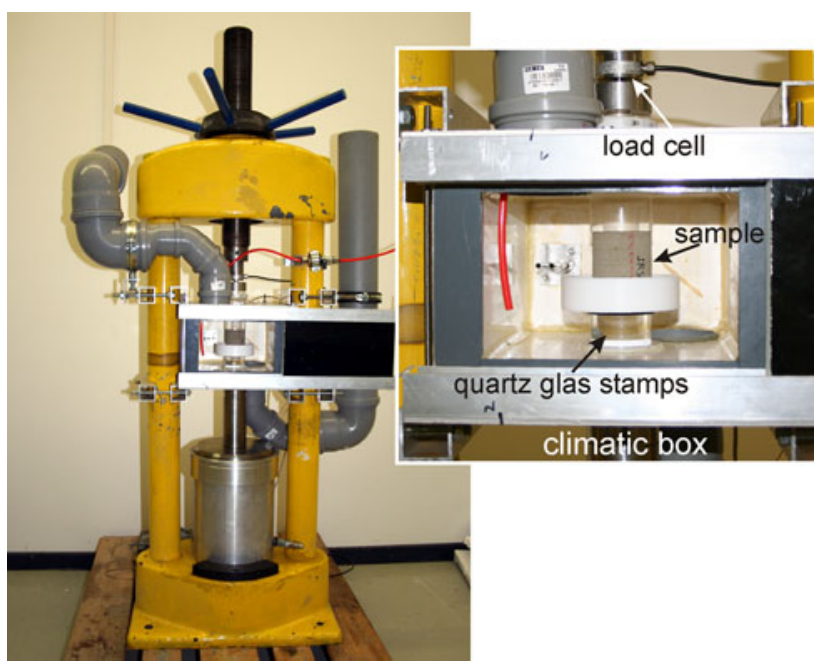

Fig. 9 Measuring apparatus for determining the swelling pressure

under both water saturated conditions and during changes of RH. To obtain more information about the swelling pressure developed during stepwise changes in the $\mathrm{RH}$ a manual rock press was modified to carry out the measurements (Fig. 9). The cylindrical samples $(\varnothing 50 \mathrm{~mm} \times 50 \mathrm{~mm})$ were restrained with a pressure in the range of 0.034 and $0.038 \mathrm{~N} / \mathrm{mm}^{2}$, between the press stamps. The load was applied to the coplanar end-faces over quartz glass stamps. Around the measurement device a climate box was installed, controlled by a climate chamber (Fig. 9). Pressure was measured by a load cell with a resolution of $0.1 \mathrm{~N}$ and an accuracy of $1 \mathrm{~N}$.

As expected, the maximum measured swelling pressure was developed by the water-saturated samples and is reported in Table 3. The swelling pressure is highest when measured perpendicular to the bedding plane (Z-direction). The maximum values measured ranged from $0.100 \mathrm{~N} / \mathrm{mm}^{2}$ for the Karlshafen to $0.028 \mathrm{~N} / \mathrm{mm}^{2}$ for the Uder sample. These values are far below, at least one order of magnitude smaller, the tensile strength measured under water saturated conditions that ranged from $7.6 \mathrm{~N} / \mathrm{mm}^{2}$ for the Tambach and $2.3 \mathrm{~N} / \mathrm{mm}^{2}$ for the Uder sandstone.

Generally, the samples show an increase of the swelling pressure with increasing moisture content. In many cases, during equilibration a decrease of stress is observable. This relaxation depends on the material and the moisture content as shown in Fig. 10 for the Sand and the Obernkirchen sandstones measured perpendicular to the bedding (Z-direction).

The RH was increased stepwise from 25 to $95 \%$ in 8 stages. For the Sand sample an incremental increase of swelling pressure was observed between 35 and $75 \% \mathrm{RH}$. At $85 \% \mathrm{RH}$, a primary increase of swelling pressure passes into a slight reduction during equilibration. $\mathrm{RH}$ exhibits only a very slight increase of pressure followed by a clear 
Fig. 10 Swelling pressure of the sandstones from Sand and Obernkirchen dependent on relative humidity, both measured perpendicular to bedding

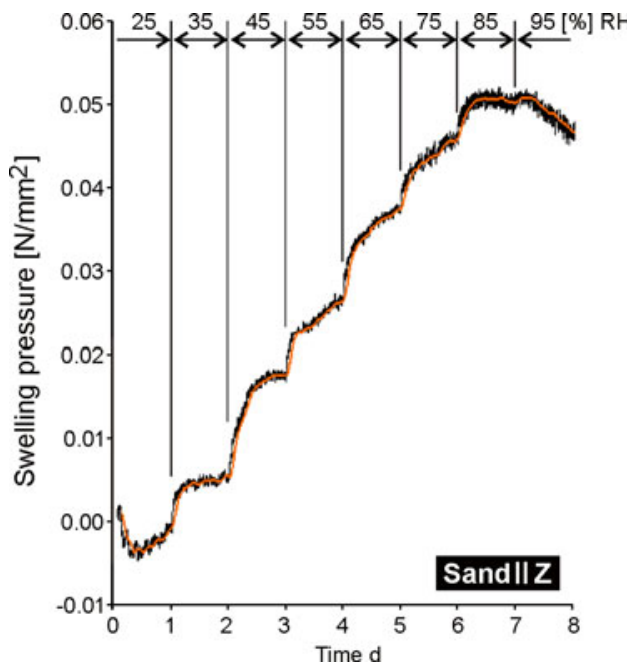

reduction at the $95 \%$ stage. The total swelling pressure obtained as a result of the final $\mathrm{RH}$ change amounts to some $0.05 \mathrm{~N} / \mathrm{mm}^{2}$. This behaviour was shown by most of the sandstones studied, except for the Obernkirchen and Uder sandstones discussed below.

The sample from Obernkirchen shows a completely different swelling pattern upon an increase in RH. In fact, for all increasing humidity stages an initial increase of pressure occurs, with a subsequent relaxation. However, only for the $35 \%$ stage a positive increase of swelling pressure can be measured even after sample equilibration. With further increased RH the relaxation during equilibration is larger than the initial increase of pressure resulting in contraction (negative swelling pressure). This behaviour was only observed for the Oberkirchen and Uder sandstone types, well-sorted sandstones with fairly equal sized pores having a radius around $10 \mu \mathrm{m}$ and with a low matrix and cement content.

The swelling pressures measured, perpendicular to the bedding plane, varied between $0.005 \mathrm{~N} / \mathrm{mm}^{2}$ for the Obernkirchen and $0.05 \mathrm{~N} / \mathrm{mm}^{2}$ for the Sand sandstone (see Fig. 10). Hence, the values are significantly lower, by over two orders of magnitude, than the tensile strength at water saturation for the respective samples $\left(4.3\right.$ and $2.9 \mathrm{~N} / \mathrm{mm}^{2}$, respectively).

\section{Discussion}

Rock fabric of sandstones

Sandstones are formed in characteristic geological settings by erosion of existing rocks followed by transport and sedimentation. The deposited detritus is consolidated by compaction and cementation during diagenesis (lithification). By post diagenetic processes additional modification of the sandstone fabric may occur.

The erosion of rocks in their source area represents the first step for the mineralogical composition and the fabric of the sandstone. The eroded source material controls the fragment composition and the grain sizes of the subsequent sediment. For example, quartz grain size distributions of the source rocks determine the grain size distributions of quartz-rich sandstones.

Transport processes of the detritus are very important because they result in a strong differentiation of the rock components and depend on chemical and mechanical resistance. In general, weathering resistant minerals such as quartz, and to a lesser extent feldspars, are enriched in many sedimentary rocks. In the process of mineralogical sorting, a grading of the grain size also takes place. Different grain sizes are transported or deposited dependent upon their densities and on the energy level of the transporting medium. Moreover, increasing transportation distances lead to increasing roundness and an increased sorting of the rock components, which defines the so-called sedimentary maturity.

The transport of sand occurs predominantly by fluvial, and secondarily by Aeolian, processes. For fluvial transported sand three main deposition areas can be distinguished: river; deltaic; and, coast or barrier depositions (cf. Potter and Pettijohn 1977). River deposits consisting of sand are normally poorly sorted with respect to mineralogical composition, having a high content of lithoclasts, and a wide range of grain size distribution. In the present study, the sandstones from Schleerieth and Sand represent such rocks which are classified as litharenite (McBride 1963). In contrast, barrier sands show a pronounced maturity of the mineralogical composition. They consist mainly of quartz and are well-sorted (more or less 
equigranular). These rocks exhibit only a few lithoclasts, which are mainly composed of quartz polycrystals. Such sandstones were classified as quartz arenites and are represented in this study by the rocks from Uder and Obernkirchen. A high quartz content and the narrow grain size distribution maximum is typical for both rocks (Fig. 4g, h). In contrast, the sandstones from Karlshafen, Lobach, Bebertal and Tambach represent transition sediments, which are also related to fluvial deposits. Possibly a long or intensive transport or a special situation in the source area resulted in a varying differentiation of the components. These rocks correspond to the sublithic arenite sandstone type following the classification of McBride (1963).

All investigated sandstones show a pronounced elongation of the detrital grains parallel to the bedding (Fig. 4a-h). This typical fabric attribute of sandstones is caused by the anisotropy of mechanical and chemical weathering resistance of the non-cubic minerals. The resulting non-isometric grains are oblate (pancake-shaped) or prolate (cigar-shaped). During transport and sedimentation the minerals were deposited or adjusted themselves parallel to the flow current. In the sedimentary unit this results in a preferred grain-shape orientation and represents a part of the bedding. This phenomenon is pronounced for minerals with extreme mechanical resistance anisotropy like micas (mainly muscovite, Fig. 4a, b).

The lithification of the fragile sands occurs during the diagenetic processes of compaction and cementation (e.g., Wilson and McBride 1977). The compaction generated by the overlying pressure of the younger sediments leads to grain rotation processes, which results in a closer packing of detrital grains. This process is accompanied by a modification of the grain contacts from point to longitudinal grain contacts (Bjørlykke 1983). During progressive compaction, pressure solution can occur, especially between quartz and feldspar grains. This process results in concavoconvex grain contacts, which is accompanied by the dissolution of weaker minerals or imperfect crystals that results in the present grain shape (Becker 1995). The dissolved substances are usually precipitated onto adjacent pore walls causing consolidation of the sediment (Houseknecht 1986). At even stronger compaction sutured grain contacts result by pressure solution (Taylor 1950). However, such grain contacts could not be identified in the studied sandstones. Among the cements produced by pressure solution and precipitation, additional phases could also be incorporated by fluid flow within the sedimentary body. In some cases, this may result in a very strong cementation by quartz and also by calcite or dolomite. Concerning the investigated sandstones, strong quartz cementation is observable for the Tambach sandstone, whereas the rocks from Lobach, Karlshafen and Bebertal exhibit multiple calcite precipitations as cements. Quartz and feldspar cements occur in the investigated sandstones as syntaxial growth fringes. They are in many cases only distinguishable due to anomalous grain shapes or by fluid inclusion paths.

Fabric dependence of physical properties

The fabric of the sandstone controls the petrophysical properties of the rock (Siegesmund and Dürrast, in press), and thus, its behaviour during weathering processes. The mineralogical composition, the assembling of particles and the empty spaces between the solid bodies plays the crucial role. Hence, the pore space represents the negative copy of the solid fabric.

For the decay of natural building stones to occur, the stresses induced by weathering have to exceed the rock strength. This is especially the case for tensile strength because it is the lowest of the material. Although the predominant mineralogical composition is comparable for sandstones (quartz, feldspar), the strength of these rocks is mainly controlled by their porosity. However, the fabric of the sandstones can also have a strong influence on its mechanical strength. The correlations of the tensile and compressive strength with regards to open porosity of the studied samples are presented in Fig. 11. There is a clear correlation between mechanical strength and open porosity, except for the Tambach sandstone, which is characterised by a much higher strength that can be explained by the strong cementation of the detrital grains by quartz growth fringes.

On the other hand, moisture transport properties are controlled by the pore size distribution (e.g., Ruedrich and Siegesmund 2006). This is shown for the water adsorption coefficient ( $w$ value) and the water vapour diffusion resistance ( $\mu$ value) in Fig. 11. Sandstones with a small average pore radius show a slow water uptake and a large vapour diffusion resistance. Sandstones with large average pore radius normally exhibit a fast water absorption and a low vapour diffusion resistance. The sandstones from Sand and Schleerieth do not follow this tendency. Both samples exhibit a bimodal pore space distribution. The high proportion of micropores leads to a low average pore radius. However, the upper pore radii maximum in the micrometer range results in a good pore connectivity that is reflected in the distinct water transport behaviour. The water transport properties play an important role for the stresses in swellable building stones induced by moisture expansion. Depending on the water transport velocities and the climatic conditions, moisture enrichment zones can originate leading to heterogeneous stress accumulations within the rock. According to the accumulation depth certain damage phenomena could be the result, for example the thin scaling of the surface or a deep-reaching crack formation far away from the surface (Snethlage and Wendler 1997). 
Fig. 11 Mechanical and water transport properties correlated to the open porosity of the studied samples. Where $\sigma_{z}$ tensile strength; $\sigma_{\text {ucs }}$ compressive strength; $w$ capillary absorption coefficient; $\mu$ water vapour diffusion resistance
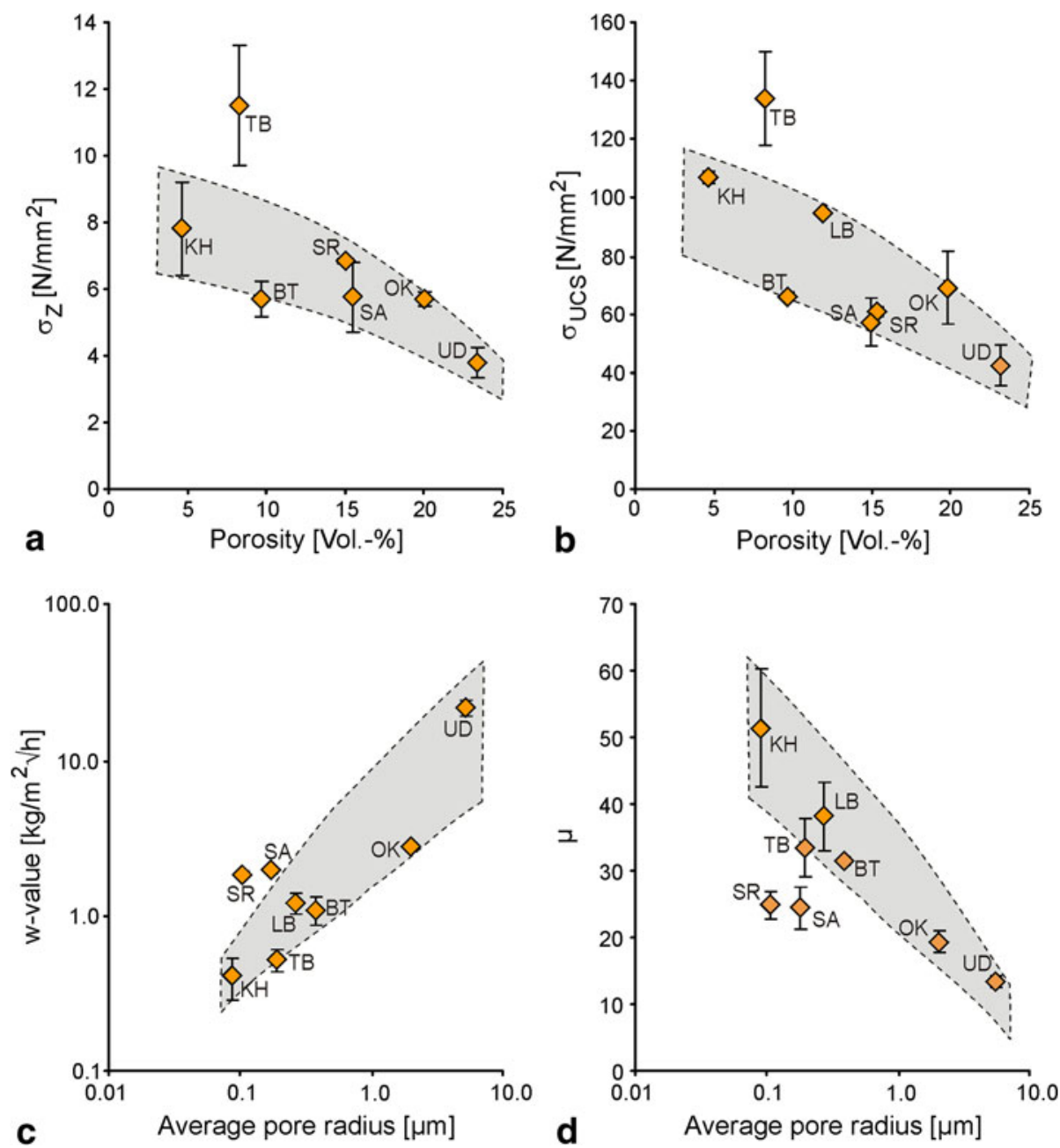

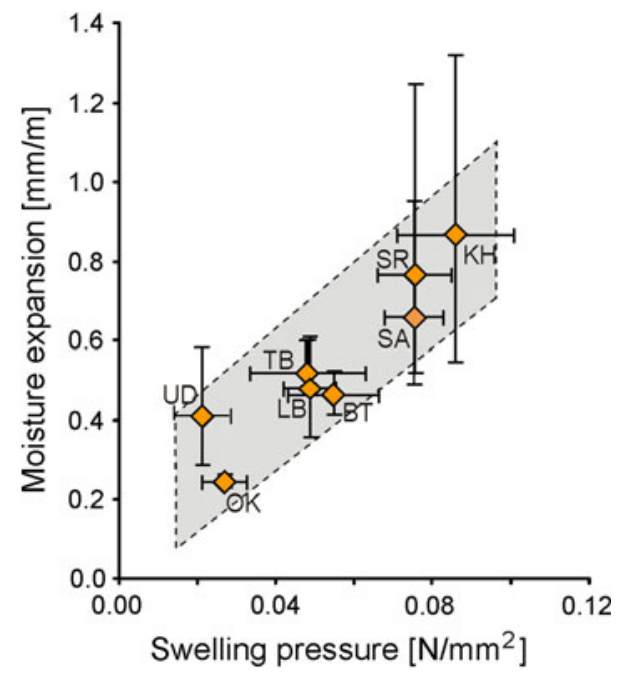

Fig. 12 Correlation between moisture expansion at water saturation conditions and swelling pressure

The studied sandstones show a clear correlation between moisture expansion and swelling pressure (Fig. 12). The maximum swelling pressure was measured before softening of the material occurred. Generally, the swelling pressures are very low, ranging between 0.028 and $0.100 \mathrm{~N} / \mathrm{mm}^{2}$, as compared to those induced by thermal expansion (cf. Kocher 2005). The values are well below the tensile strength of the samples, even when they are water-saturated $\left(2.3-7.6 \mathrm{~N} / \mathrm{mm}^{2}\right)$. Thus, no damages can be expected for the investigated sandstones generated by stresses due to moisture expansion since even the lowest tensile strength of these stones is over ten times the pressure induce by this mechanism.

Swellable clay mineral content based on XRD and CEC results

In spite of the comprehensive investigations which were carried out, the real cause for the moisture expansion observed, either under hygric or hydric conditions, remains unclear. It is most likely to be an interaction between different processes. The clay mineral content of the investigated sandstones is low because of their original sedimentation process and the diagenetic overprint. During 
deposition of sands the energetic level of the transport medium was too high for clay sedimentation. If sand and silt components are deposited, the clay content remains in suspension. During the diagenetic overprint, in general, kaolinite and illite are developed by alteration of detrital mineral phases (Worden and Morad 2002). Only lithoclasts could be the cause for a significantly higher portion of swellable clay minerals in sandstones. Exceptions are clay rich layers in sandstones which result during a decrease of the energetic level of the fluvial regime. However, such layers were not present in the sandstones considered in this study.

The slight clay mineral content that can be assumed for sandstones due to general geological processes is supported for the investigated rocks by the XRD data. Only in the sandstones from Karlshafen and Bebertal was smectite identified in the fraction $<2 \mu \mathrm{m}$ (Fig. 5). Swellable mixed layer minerals (containing "smectitic interlayers") were also detected in the sandstone from Sand. The main clay minerals for all the sandstones are illite and subordinated kaolinite. The rocks from Sand, Schleerieth and Karlshafen also contain chlorite.

XRD quantification of small amounts of clay minerals is not easy (Moore and Reynolds 1997; Dohrmann et al. 2009). Even the application of the Rietveld method still fails when mixed layer clay minerals are present (Ufer et al. 2008a). However, some advances have been made to overcome this problem in the future (see Ufer et al. 2008b). Nonetheless, the CEC method could be used as an approximation to determine if expandable clay minerals are dominant or not (Dohrmann and Kaufhold 2010).

Sandstones contain minerals that differ markedly in terms of their CEC. CEC commonly results from negative charges of clay minerals and organic material. Organic material contains only $\mathrm{pH}$-variable charges, whereas charges originating from clay minerals are predominantly permanent. Detrital minerals such as quartz, feldspar, carbonates, sulphates, and heavy minerals usually have CEC values close to the detection limit. Micas have a very low CEC as well (Weiss 1958). Among the clay minerals, kaolinite has the lowest CEC (1-10 meq/100 g, Lagaly 1993). CEC values for illite and chlorite were reported in the range of 10-40 meq/100 g (Grim 1968). However, in general illites are defined as minerals which contain up to $5 \mathrm{wt} \%$ smectitic layers, the so-called "frayed edge sites" (Moore and Reynolds 1997). Accordingly, a significant portion of the total CEC measured for an illite stems from these smectitic layers. The highest CEC of all clay minerals is determined for smectites (swellable clay minerals): $70-120 \mathrm{meq} / 100 \mathrm{~g}$ (Lagaly 1993). Theoretically, vermiculites may have even higher CEC values. However, the layer charge densities of these minerals are as high as the values of illites, which results in a limited mobility of exchangeable cations in the interlayer spaces of vermiculites (and collapsed interlayer spaces for illites) causing much lower CEC values when direct CEC measurements are compared to those for smectites.

Clay minerals can be stacked on each other in variable amounts and with variable degrees of ordering; these minerals are called mixed layers. The most frequent sedimentary mixed layer minerals are of the illite-smectite type. The CEC of such minerals is as variable as the relative proportions of the components. A 50:50 mixture should have a CEC of $50 \%$ illite and $50 \%$ smectite, which would add up to approximately $40-80 \mathrm{meq} / 100 \mathrm{~g}$ depending on the crystallochemical composition of the components and their degree of weathering. In brief, the CEC could be used to detect predominance of swellable (=smectitic) layers if CEC exceeds, for example, 50 meq/ $100 \mathrm{~g}$ in the clay fraction, assuming that this fraction contains only clay minerals.

Results of CEC analyses of bulk samples are very low, which is typical for sandstones. Clay fractions of the sandstones are enriched in clay minerals resulting in a much higher CEC. However, the absolute values are much lower than the proposed $50 \mathrm{meq} / 100 \mathrm{~g}$. All clay fractions contain non-clay minerals in significant amounts. For the samples of Karlshafen, Bebertal and Tambach, the nonclay fraction was found to be mostly quartz and feldspar plus calcite. These minerals dilute the CEC values of the clay fractions, thus complicating the differentiation with respect to establishing a correlation between CEC and the amounts of swellable clay minerals present.

Two sandstones, Uder and Lobach, did not show any significant CEC (values below $0.5 \mathrm{meq} / 100 \mathrm{~g}$, Table 1). Three contain swellable clay minerals. Two of these samples contain smectites (together with illite): Bebertal (CEC: $1 \mathrm{meq} / 100 \mathrm{~g}$ bulk rock and $8.6 \mathrm{meq} / 100 \mathrm{~g}$ in the clay fraction) and Karlshafen (CEC: 2.0/11.7 meq/100 g bulk/ clay). Karlshafen also contains some kaolinite. Both sandstones contain $6 \mathrm{wt} \%<2 \mu \mathrm{m}$. The third sandstone Sand (CEC: $3.4 / 15.2 \mathrm{meq} / 100 \mathrm{~g}$ bulk/clay, fraction $<2 \mu \mathrm{m}: 16 \mathrm{wt} \%)$ contains traces of expandable illite-rich illite-smectite mixed layers together with chlorite, illite, and kaolinite. All three fractions $<2 \mu \mathrm{m}$ have intermediate CEC values.

The other three sandstones contain no swellable clay minerals. Sample Schleerieth (CEC: $2.1 / 5.4 \mathrm{meq} / 100 \mathrm{~g}$ bulk/clay, fraction $<2 \mu \mathrm{m}$ : $21 \mathrm{wt} \%$ ) contains chlorite and illite. Sandstone Tambach (CEC: 1.0/4.8 meq/100 g bulk/ clay) is rich in illite with traces of chlorite. The lowest CEC $(0.3 / 2.2 \mathrm{meq} / 100 \mathrm{~g}$ bulk/clay) and the lowest illite content was detected for sandstone Obernkirchen.

In one of each group (with/without smectite) lithoclasts are present. An extended fractionation was performed to determine the silt fractions $(2-6.3,6.3-20$, and $20-63 \mu \mathrm{m})$ of these sandstones in addition to the clay fractions. 
The smectitic sample Sand has higher CEC values for all the silt fractions compared to the non-smectitic sample Schleerieth. XRD results confirm the presence of swellable clay minerals in each of the fractions. The CEC values of Sand decrease with increasing grain size as reported in Table 1. Though this is not surprising it suggests that clay minerals are aggregated and act as cement between sand grains or fill pores. The CEC of the separated clay and silt fractions of Schleerieth was only moderately larger than that for the bulk rock sample correlating with the absence of smectitic layers while confirming the presence of aggregated clay minerals in coarser fractions (lithoclasts).

The presence of partly expandable clay minerals was confirmed and CEC correlates well with moisture expansion by hydric wetting (Fig. 13). On the other hand, the sandstones Tambach and Obernkirchen have very low CEC values, but still moisture expansion is detectable suggesting

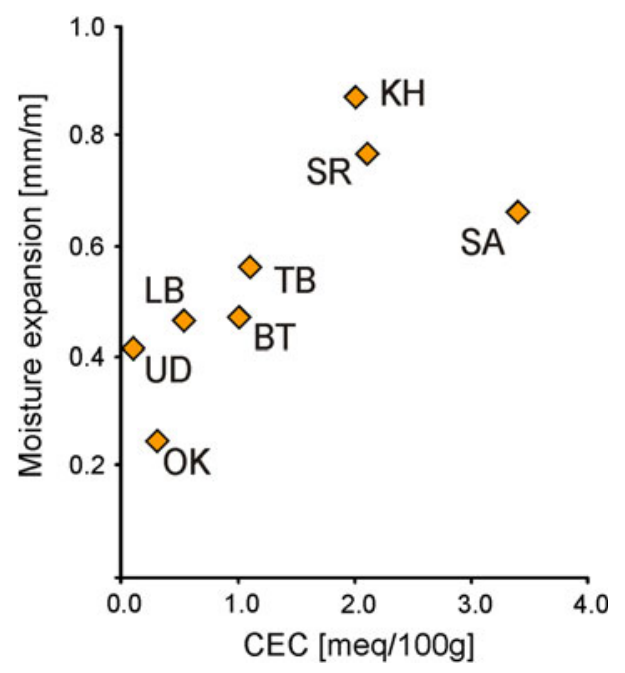

Fig. 13 Moisture expansion at water saturated conditions versus CEC-values of the investigated sandstones that other processes may be responsible for the observed expansion behaviour.

Moisture expansion as a function of pore space properties

A good correlation is observable for the average pore radius and the extent of moisture expansion. With decreasing average pore radius an increase in moisture expansion occurs (Fig. 14a). The same trend is detectable for a portion of the micro-porosity. The higher the microporosity, the larger is the moisture swelling magnitude (Fig. 14b). Thus, the main cause of the swelling and shrinking due to changes in moisture content can be the disjoining pressure in small pores.

The main swelling mechanisms, i.e., osmotic, crystalline and disjoining pressure, are difficult to distinguish based on the observed moisture expansion processes in sandstones. The presence of clays plays an important role, because these small mineral grains generate small pores in sandstones. But whether the expansion is due to the small pores or the presence of clays cannot be differentiated. However, the occurrence of clay minerals within the rock fabric, e.g., in clay-rich lithoclasts, is critical since these have the ability of transferring stresses within the rock fabric, whereas clay mineral coatings in the pores normally have adequate space for swelling and would therefore not result in the development of swelling pressures (Fig. 15).

Softening properties as a function of moisture content

Natural building stones show a decrease in strength upon wetting, which is described in the literature as softening (cf. Hirschwald 1908). The softening degree varies with the different lithotypes. For crystalline rocks, such as granites and gneisses, the softening effect is small. However, this effect can be significant in porous rocks such as sandstones
Fig. 14 Moisture expansion at water saturated conditions versus average pore radius and micro-porosity of the investigated sandstones
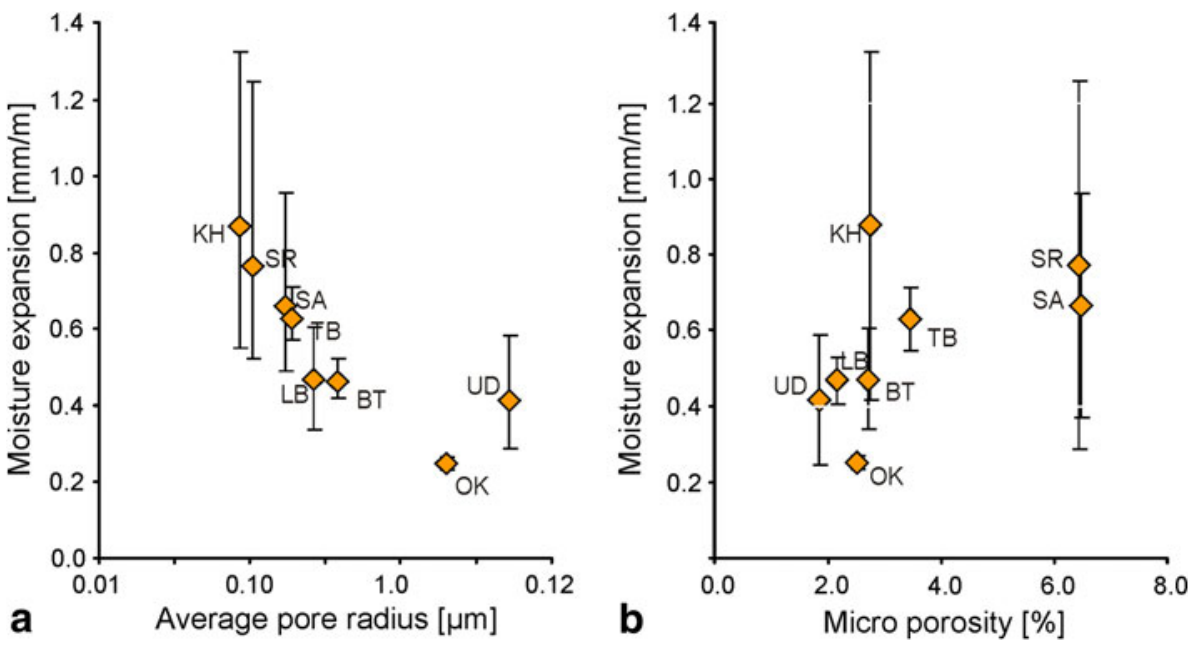
Fig. 15 Sketch depicting the different ways clay minerals occurs in sandstones
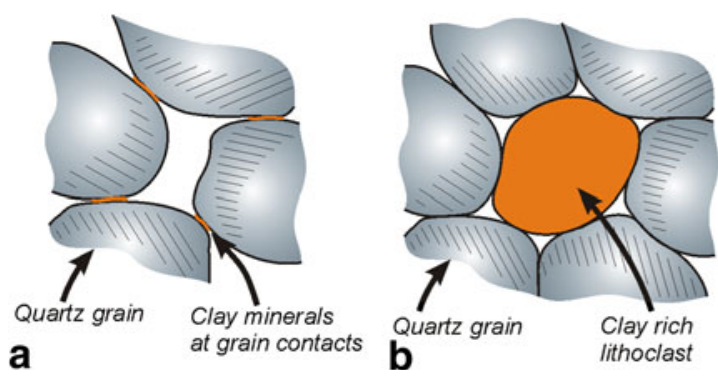

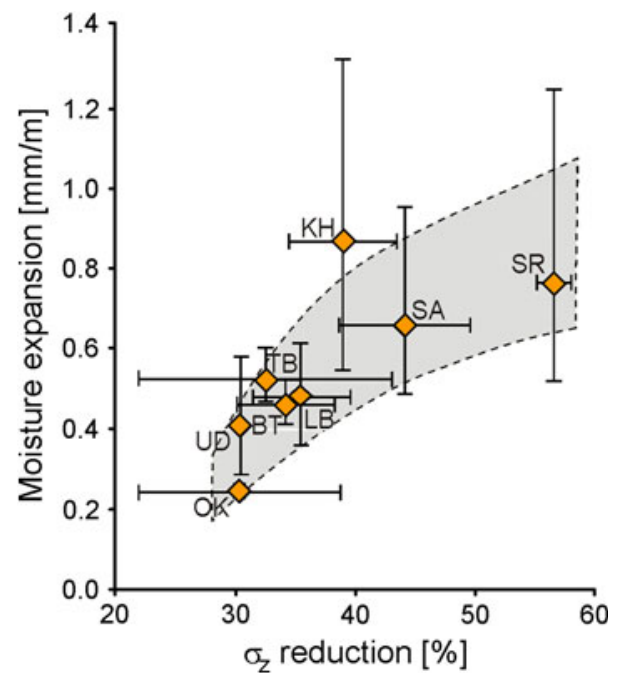

Fig. 16 Moisture expansion at water saturated conditions versus tensile strength reduction

and tuffs and can reach a strength decrease of up to $50 \%$ (Siedel 2010). In sandstones, Vasarhelyi (2004) found a linear relationship between the compressive strength during dry and water-saturated conditions. Morales Demarco et al. (2007) found a positive correlation between the decrease of the compressive strength and the magnitude of moisture expansion in sandstones. This correlation has been verified for the tensile strength of sandstones in the present study (Fig. 16). Morales Demarco et al. (2007) show that the strength reduction depends on the degree of saturation. A low degree of saturation for all sandstones studied lead to a strong reduction in the compressive strength. At increasing degrees of saturation, sandstones with a small proportion of micropores and a slight moisture expansion only show a small increase in strength reduction. In contrast, sandstones with a large amount of micropores and pronounced moisture expansion exhibit a progressive strength reduction at increasing saturation levels. This suggests that there is a relationship between the pore sizes present in the stone, the saturation degree, the intensity of moisture swelling and the strength reduction, i.e., the rock softening of sandstones.

The saturation degrees at different $\mathrm{RH}$ stages were calculated from sorption measurements and combined with results from capillary water absorption tests. Two general patterns can be determined when plotting the degrees of saturation versus corresponding moisture expansion values at respective moisturisation in the sandstones (Fig. 17). Sandstones with only a slight moisture expansion and a very low micropore content, such as the Uder and Obernkirchen samples, exhibit a strong swelling-compared to the total expansion they can undergo-at low degrees of saturation. The other six sandstones, with a large number of micropores, also show a strong swelling at low degrees of saturation, but this continues to increase with increasing saturation resulting in a high expansion.

Sorption of water in very small pores due to condensation mechanisms may act contrary to the moisture expansion as it serves the formation of concave menisci in the pore gaps resulting in negative capillary pressures (Weimann 2001) that generate a tensile stress. The negative
Fig. 17 Moisture expansion versus degree of saturation for the different humidity conditions between $15 \%$ and 95\% RH for the sandstones from a Uder and b Karlshafen
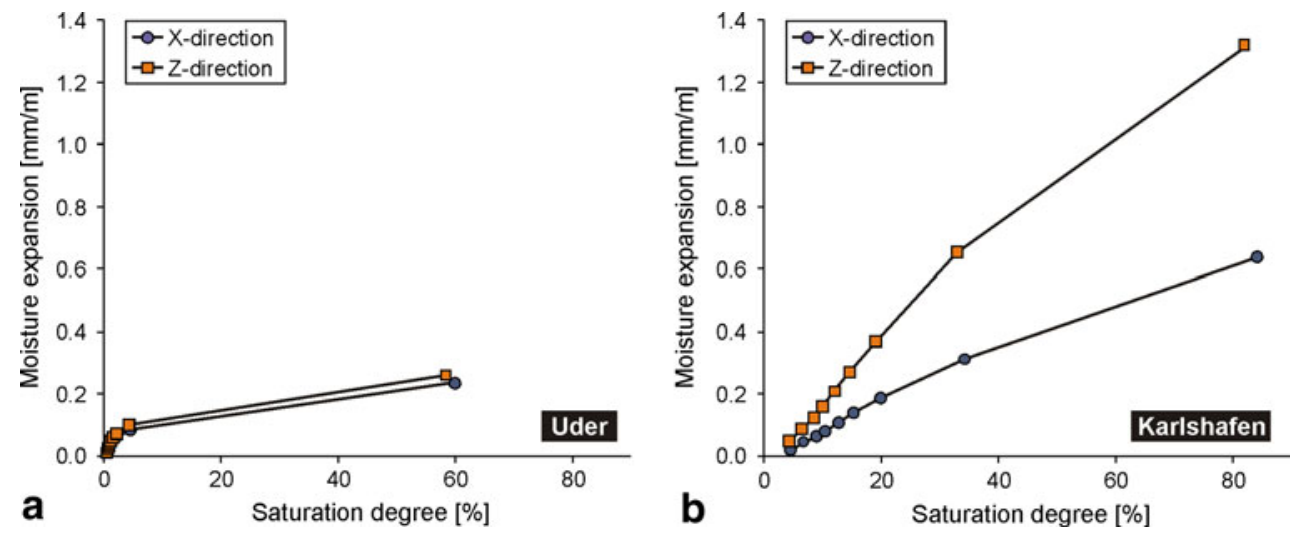
pressure rises with decreasing pore radii and decreases with increasing water content due to the flattening of the menisci. In larger pores, no capillary condensation takes place as only a few molecular layers accumulate at the mineral surfaces and these can only induce slight negative stresses. Therefore, sandstones containing a low number of micropores experience a relative large swelling at low degrees of saturation. For sandstones with a high proportion of micropores, the negative pressure descends with increasing saturation and result in a continuous increase in swelling with increasing moisture content that might be attributed to disjoining pressure.

The study has shown that there is a clear correlation between the pore size, the degree of water saturation, the intensity of moisture swelling and the softening of sandstones. It has been clearly established that the presence of micropores plays a significant role, since these pores will be the first to condense water. Thus, it appears that it is the presence of liquid water in the pores that induces the swelling behaviour observed. Therefore, the terms hygric and hydric should only be used to describe the testing conditions, while the actual swelling is caused by the moisture present in the micropores.

That clay minerals, especially those present in lithoclasts in the rock, play a role is not under discussion. But it is clear that not all the moisture related expansion can be attributed to them. Rather, their contribution may be related to their contribution in the creation of microporosity. Therefore, it would appear that the disjoining pressure may be more relevant for those rocks not containing significant amounts of swellable clays, such as marbles or granites.

Acknowledgments We are grateful to K. Wemmer and S. Kaufhold for their help with the mineral analysis. Special thanks go to E. Charola for the scientific discussion and the editorial assistance. Our work was supported by the Deutsche Bundesstiftung Umwelt.

Open Access This article is distributed under the terms of the Creative Commons Attribution Noncommercial License which permits any noncommercial use, distribution, and reproduction in any medium, provided the original author(s) and source are credited.

\section{References}

Becker A (1995) Quartz pressure solution: influence of crystallographic orientation. J Struct Geol 17:1395-1405

Bjørlykke K (1983) Diagenetic reactions in sandstones. In: Parker A, Sellwood BW (eds) Sediment diagenesis. D. Reidel Publishing Company, Dordrecht, pp 169-213

Blöchl B, Kirchner D, Stadlbauer E (1998) Die hygrische Dehnung von Baumberger Kalksanstein - tonmineralogische und gesteinsphysikalische Aspekte

Butt HJ, Graf K, Kappel M (2003) Physics and chemistry of interfaces. Wiley-VCH, New York. ISBN 3-527-40413-9
De La Calle C, Suquet H (1988) Vermiculite. In: Bailey SW (ed) Hydrous phyllosilicates. Reviews in Mineralogy. Mineralogical Society of America, vol 19, pp 455-496

Delgado Rodrigues J, Charola AE (1996) General report on water repellents. Sci Technol Cult Heritage 5:93-103

Derjaguin BV, Obukov EV (1936) Anomalien dünner Flüssigkeitsschichten III Acta Physicochim. URSS 5(1):1-22

Dixon JB, Weed SB (1989) Minerals in soil environments, 2nd edn. Soil Science Society of America, pp 1244

Dohrmann R, Kaufhold S (2009) Three new, quick CEC methods for determining the amounts of exchangeable calcium cations in calcareous clays. Clays and Clay Minerals 57(3):251-265

Dohrmann R, Kaufhold S (2010) Determination of exchangeable calcium of calcareous and gypsiferous bentonites. Clays and Clay Minerals 58:513-522

Dohrmann R, Rüping KB, Kleber M, Ufer K, Jahn R (2009) Variation of preferred orientation in oriented clay mounts as a result of sample preparation and composition. Clays and Clay Minerals 57:686-694

Graf v. Reichenbach H, Beyer J (1995) Dehydration and rehydration of vermiculites: II. Phlogopitic Ca-vermiculite. Clay Miner 30:273-286

Grim RE (1968) Clay mineralogy. McGraw Hill, London, p 596

Gründer J (1980) Über Volumenänderungsvorgänge in überkonsolidierten, diagenetisch verfestigten Tonen und ihre Bedeutung für die Baupraxis. Geotechnik 2:60-66 (Essen)

Heim D (1990) Tone und Tonminerale: Grundlagen der Sedimentologie und Mineralogie. Enke Verlag, Stuttgart, p 157

Hirschwald J (1908) Die Prüfung der natürlichen Bausteine auf ihre Wetterbeständigkeit. Z. prakt. Geologie 16:257-264

Houseknecht DW (1986) Intergranular pressure solution in four quartzose sandstones. J Sed Petrol 58:228-246

Jasmund K, Lagaly G (1993) Tonminerale und Tone. Struktur, Eigenschaften, Anwendung und Einsatz in Industrie und Umwelt. Steinkopff Verlag, Darmstadt: S., p 490

Jimenez Gonzalez I, Scherer G (2004) Effect of swelling inhibitors on the swelling and stress relaxation of clay bearing stones. Environ Geol 46:364-377

Kahr G (1986) Wasseraufnahme und Wasserbewegung in hochverdichtetem Bentonit. NAGRA, Technischer Bericht, pp 14-86

Kocher M (2005) Quelldruckmessungen und thermische Druckmessungen an ausgewählten Sandstein. Diss., Universität München:S, p 129

Lagaly G (1993) Reaktionen der Tonminerale. In: Jasmund K, Lagaly G (eds) Tonminerale und Tone. Steinkopff, Germany, p 490

Lagaly G (1997) Dispersionen und Emulsionen. Steinkopff Verlag, Germany

Laird DA (2006) Influence of layer charge on swelling of smectites. Appl Clay Sci 34:74-87 London

Madsen FT (1976) Quelldruckmessungen an Tongesteinen und Berechnung des Quelldrucks nach der DLVO-Theorie. Mitteilungen des Institutes für Grundbau und Bodenmechanik, ETH Zürich, vol 108:S., p 65

Madsen FT, Müller-Vonmoos M (1988) Das Quellverhalten der Tone. - Mitteilungen des Institutes für Grundbau und Bodenmechanik, ETH Zürich, vol 133:S., pp 39-50

Madsen FT, Müller-Vonmoos M (1989) The swelling behaviour of clays. Appl Clay Sci 4:143-156

Madsen FT, Nüesch R (1990) Langzeitquellverhalten von Tongesteinen und tonigen Sulfatgesteinen. Mitteilungen des Institutes für Grundbau und Bodenmechanik, ETH Zürich, vol 140:S., p 51

McBride EF (1963) A classification of common sandstones. J Sed Petrol 33(3):664-669

Meier LP, Kahr G (1999) Determination of the cation exchange capacity (CEC) of clay minerals using the complexes of copper 
(II) ion with triethylenetetramine and tetraethylenepentamine. Clays Clay Miner 47:386-388

Moore DM, Reynolds RC Jr (1997) X-ray diffraction and the identification and analysis of clay minerals. Oxford University Press, Oxford, p 332

Morales Demarco M, Jahns E, Ruedrich J, Oyhantcabal P, Siegesmund S (2007) The impact of partial water saturation on rock strength: an experimental study on sandstone. Zeitschrift Deutsche Geologische Gesellschaft, Band 158:869-882

Müller-Vonmoos EE, Kohler M (1993) Geotechnik und Entsorgung. In: Jasmund K, Lagaly $\mathrm{G}$ (eds) Tonminerale und Tone. Steinkopff Verlag, Germany

Potter PE, Pettijohn FJ (1977) Paleocurrents and basin analysis; second, corrected and updated edition. Springer, Berlin

Ruedrich J, Siegesmund S (2006) Fabric dependence of length change behaviour induced by ice crystallisation in the pore space of natural building stones. In: Fort $\mathrm{R}$, Alvarez de Buergo $\mathrm{M}$, Gomez-Heras M, Vazquez-Calvo C (eds) Heritage, Weathering and Conservation 1:597-505

Ruedrich J, Kirchner D, Seidel M, Siegesmund S (2005) Deterioration of natural building stones induced by salt and ice crystallisation in the pore space as well as hygric expansion processes. In: Siegesmund S, Auras M, Ruedrich J, Snethlage, R (eds) Geowissenschaften und Denkmalpflege. Zeitschrift Deutsche Geologische Gesellschaft 156/1:59-73

Schuh H (1987) Physikalische Eigenschaften von Sandsteinen und ihren verwitterten Oberflächen. Münchner Geowiss. Abh., 6: S.; Enke Verlag, Stuttgart, p 66

Schult A, Shi G (1996) Hydration swelling of crystalline rocks. Geophys J Int 131:179-186

Siedel H (2010) Historic building stones and flooding: changes of physical properties due to water saturation. J Perf Constr Fac 24:452-461

Siegesmund S, Dürrast $\mathrm{H}$ Mechanical and physical properties of rocks. In: Siegesmund S, Snethlage R (eds) Stone in architecture. Springer, Verlag (in press)

Snethlage R, Wendler E (1997) Moisture cycles and sandstone degradation. In: Baer NS, Snethlage R (eds) Saving our architectural heritage, the conservation of historic stone structures. Elsevier, Chichester, pp 7-24

Snethlage R, Wendler E, Klemm DD (1995) Tenside im Gesteinsschutz - bisherige Resultate mit einem neuen Konzept zur Erhaltung von Denkmälern aus Naturstein. In: Snethlage R (Hrsg.): Denkmalpflege und Naturwissenschaft - Natursteinkonservierung I. Verlag Ernst \& Sohn, Berlin, pp 127-146
Splittgerber H (1976) Spaltdruck zwischen Festkörpern und Auswirkungen auf Probleme in der Technik. Cement Concrete Res 6:29-34

Steindlberger E (2004) Volcanic tuffs from Hesse (Germany) and their weathering behaviour. Environ Geol Special Issue Stone Decay Hazards 46(3-4):378-390

Stockhausen N (1981) Die Dilatation hochporöser Festkörper bei Wasseraufnahme und Eisbildung. Diss. TU München:S., p 163

Taylor JM (1950) Pore-space reduction in sandstones. Bull Am Assoc Petrol Geol 34:701-716

Ufer K, Stanjek H, Roth G, Dohrmann R, Kleeberg R, Kaufhold S (2008a) Quantitative phase analysis of bentonites by the Rietveld method. Clays Clay Miner 56:272-282

Ufer K, Kleeberg R, Bergmann J, Curtius H, Dohrmann R (2008b) Refining real structure parameters of disordered layer structures within the Rietveld method. Z Kristallog Suppl 27:151-158

van Brakel J, Modry S, Svata M (1981) Mercury porosimetry: state of the art. Powder Technol 29:1-12

Vasarhelyi B (2004) Statistical analysis of the influence of water content on the strength of the Miocene limestone. Rock Mech Rock Eng 38(1):69-76

Weimann MB (2001) Hygrische Eigenschaften von Polymerbeton im Vergleich zu porösen mineralischen Werkstoffen im Bauwesen. Diss. Technische Hochschule Zürich, p 149

Weiss A (1958) Der Kationenaustausch bei den Mineralen der Glimmer-, Vermiculit- und Montmorillonitgruppe. Z. anorg. allgem. Z Anorg Allgem Chem 297:257-360

Weiss G (1992) Die Eis und Salzkristallisation im Porenraum von Sandsteinen und ihre Auswirkung auf das Gefüge unter besonderer Berücksichtigung gesteinsspezifischer Parameter. Münchner Geowissenschaftliche Abhandlungen, Reihe B, vol 9:S., p 62

Weiss T, Siegesmund S, Kirchner D, Sippel J (2004) Insolation weathering and hygric dilatation as a control on building stone degradation. Environ Geol 46(3-4):402-413

Wilson JC, MCBride EF (1977) Compaction and porosity evolution of pliocene sandstones, Ventura Basin, California. AAPG Bull 72:664-681

Worden RH, Morad S (2002) Clay minerals in sandstones: controls on formation, distribution and evolution: In: Worden RH, Morad S (eds) Clay mineral cements in sandstones. Special Publication of the IAS, vol 34, pp 5-40

Yariv S, Cross H (1979) Geochemistry of colloid systems. Springer, Verlag, p 450 